\title{
29. COMPARISON OF LABORATORY AND LOGGING DATA FROM LEG 129 AND THE INVERSION OF LOGS TO DETERMINE LITHOLOGY ${ }^{1}$
}

\author{
Andrew T. Fisher, ${ }^{2}$ Lewis Abrams, ${ }^{3}$ and William H. Busch ${ }^{4}$
}

\begin{abstract}
Coring during Ocean Drilling Program Leg 129 in the western Pacific resulted in poor to fair recovery, often less than $10 \%$. meaning that sedimentary sections have been poorly characterized through description of the cores. This study is an attempt to better characterize the sediments over parts of the drilled intervals, using continuous wireline-logging measurements. Laboratory and log data are presented and compared to establish which intervals are well represented by the recovered cores. Rebound corrections are applied to sediments containing a significant proportion of clay, as these materials seem to have most closely followed standard compactional trends for deep-sea sediments. Laboratory and log measurements are then used to establish five idealized lithotypes, end-member components that can be mixed to generate a variety of sediment compositions and properties. The log data are then inverted to determine the proportions of each of these lithotypes represented at every measurement depth. Examination of trends in the proportions of the five lithotypes reveals sedimentological relationships that were not apparent in the cores, largely because core recovery was strongly biased. The results of this exercise are qualitatively satisfying, but more quantitative log inversion would probably require significantly higher recovery in order to constrain possible lithotypes, both physically and chemically.
\end{abstract}

\section{INTRODUCTION}

Three sites were drilled and cored during Ocean Drilling Program (ODP) Leg 129 to the Pigafetta and East Mariana basins, yielding a wide variety of sediment and rock types and ages. One to four samples of typical lithologies from every core were collected and run through a series of standard tests to determine physical properties. Wireline logs were also run at all three sites in an effort to obtain continuous data from the sedimentary section; these logs cover only a part of the sedimentary section at each site, and no logs were run in basement. The logs are particularly important because overall recovery within the sedimentary sections was fair to poor. Several hundred-meter intervals are characterized by rock representing $<5 \%$ of that drilled and cored.

The purpose of this study is to use physical properties and log measurements made during the cruise, and geochemical data collected after the cruise, to (1) better characterize the physical state of the sediments, (2) establish some degree of ground-truth for both lab and borehole measurements, and (3) provide a qualitative assessment of the distribution of lithotypes that would be present in "representative" sections from these sites, if such complete records could be obtained.

\section{Sediments Drilled and Cored during Leg 129}

Site 800 was the first drilled during Leg 129 , and is located in the northeastern Pigafetta Basin, at about $22^{\circ} \mathrm{N}$ (Fig. 1; Brenner and Angell, this volume; Shipboard Scientific Party, 1990a). Sediments from Site 800 range in age from younger than Pliocene to Early Cretaceous, with the greatest representation by Aptian and Albian material. The sedimentary section was divided into five primary

\footnotetext{
'Larson, R. L., Lancelot, Y., et al., 1992. Proc. ODP, Sci. Results, 129: College Station, TX (Ocean Drilling Program).

${ }^{2}$ Ocean Drilling Program and Department of Geophysics, Texas A\&M University, 1000 Discovery Drive, College Station, TX 77845-9547, U.S.A

${ }^{3}$ Graduate School of Oceanography, University of Rhode Island, Narragansett. Rhode Island, 02882-1197, U.S.A.

${ }^{4}$ Department of Geology and Geophysics, University of New Orleans, New Orleans, LA 70148 , U.S.A.
}

lithologic units by the Shipboard Scientific Party (1990a), only three of which include significant coverage by wireline logs: Unit II-brown chert and porcellanite; Unit III-gray chert and limestone; and Unit IV-redeposited volcaniclastics (sandstone, siltstone and claystone). Recovery ranged from extremely poor in Units II and III ( $3.5 \%-7.3 \%, 5.1 \%$ overall) to excellent in parts of Unit IV ( $>80 \%$ in some cores, $42.7 \%$ overall). Although these divisions, and those that followed at the remaining sites, appear to be obvious from the core descriptions and site chapters in Lancelot, Larson, et al. (1990), a quick examination of the barrel sheets and logs reveals that each lithologic unit is actually a complex mixture of many different sediment types. In general, the lithologic unit boundaries were positioned at the first significant occurrence of a major lithologic change (usually a change in sediment type that suggested a change in depositional facies), although for any particular unit, sediments typical of overlying and underlying units commonly appear throughout (Lancelot, Larson, et al., 1990).

Two holes included coring within the sedimentary section at Site 801 (Fig. 1; Brenner and Angell, this volume; Shipboard Scientific Party, 1990b), yielding five lithologic units, three of which were covered by wireline logs: Unit II-brown chert and porcellanite; Unit III-volcaniclastic turbidites and minor pelagic intervals; and Unit IV - brown radiolarite. Unit III provided poor-fair recovery (20.9\% overall) whereas recovery in Units II and IV was extremely poor, averaging only $4.8 \%$. Sediments at Site 801 ranged in age from younger than Paleocene to Middle Jurassic, with the greatest representation of mid-Cretaceous material. Although Site 801 is located about $500 \mathrm{~km}$ to the southeast of Site 800 , several of the lithologic units appear to correlate well between the sites, in terms of their compositions, if not ages: Site 800, Unit II correlates with Site 801, Unit II; Site 800, Unit IV correlates with Site 801, Unit III; and Site 800, Unit V correlates with Site 801, Unit IV (Karpoff, this volume; Shipboard Scientific Party, 1990a,b). This correlation allows some comparison and combination of physical properties and log responses in order to characterize the typical properties of individual sedimentary units, as described later.

A single hole was drilled at Site 802, located in the East Mariana Basin, approximately $830 \mathrm{~km}$ southwest of Site 801 (Fig. 1; Brenner and Angell, this volume; Shipboard Scientific Party, 1990c). Sediments recovered while drilling Hole $802 \mathrm{~A}$ ranged in age from Quaternary to Early Cretaceous, with the greatest representation by 


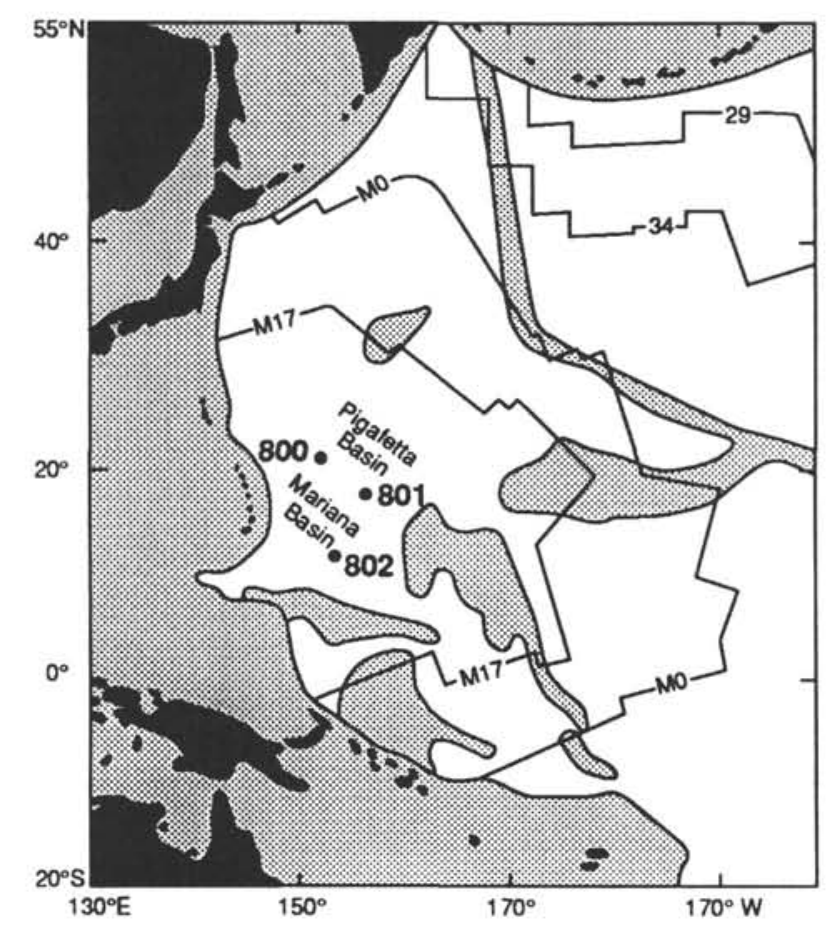

Figure 1. Locations of ODP Sites 800,801 , and 802 in the western Pacific (Lancelot, Larson, et al., 1990).

Miocene material. These materials yielded nine lithologic units, only two of which were logged: Unit II-volcaniclastic turbidite tuffs, and Unit III-nannofossil chalk. Recovery was poor to good in both of these units, ranging from $2 \%$ to $80 \%$, and was $23.4 \%$ overall. This site was separated from those in the Pigafetta Basin by a major morphotectonic boundary, a seamount province and fracture zone, which strongly influenced sediment distribution; sediments in Units II and III at Site 802 do not correlate well (by age or composition) with sediments from either Site 800 or 801 (Shipboard Scientific Party, 1990c).

\section{Biased Sampling}

In addition to being extremely poorly sampled overall because of low recovery, many of the lithologic units recovered during Leg 129 were sampled nonrepresentatively. For example, the small chunks of chert and limestone brought back to the surface when cutting cores from lithologic Unit III in Hole 800A are a biased sample of the sediments penetrated, as there is good evidence that these two lithologic types compose less than half of the stratigraphic sequence of the unit. First, the drillers reported alternating hard and soft intervals, particularly when penetrating zones where very hard materials such as chert, limestone, porcellanite, and radiolarite were the only rocks recovered (and where recovery was typically extremely low). Second, the interval velocities determined from site surveys in this area indicate that the average acoustic velocity through the sedimentary sections is near $2 \mathrm{~km} / \mathrm{s}$ at all three sites, yet the hard lithologies listed previously yielded significantly greater laboratory velocities (Lancelot, Larson et al., 1990). Similarly, sonic logs through several intervals that yielded low recovery of only very hard material suggest in-situ sediment velocities that are significantly lower than the velocities measured on samples from cores within these intervals.

Additional biases were also introduced because of the specific interests of the shipboard party and the techniques used for sample collection and testing. Several specialists sampled primarily silicarich intervals (Behl et al., this volume; Karl and Karpoff, this volume) whereas others measured the bulk geochemistry of samples that could be squeezed for pore fluids (France-Lanord et al., this volume). As a result, our knowledge of the composition of materials drilled and cored during Leg 129 is not only limited, but also strongly skewed.

\section{EXPERIMENTAL METHODS}

Shipboard physical properties and logging measurement techniques are described in detail in Lancelot, Larson et al. (1990), and only a brief review is provided here. Within each core, shipboard physical-properties scientists sampled both representative and unusual lithologic types to characterize the recovered materials. Volumes of dry samples (approximately $10 \mathrm{~cm}^{3}$ ), determined using a helium-displacement pycnometer, and wet and dry masses, measured with an electronic balance, were used to calculate bulk and grain densities, porosities, and water contents. These data were checked by gamma-ray attenuation porosity evaluator (GRAPE) (Boyce, 1976) and found to be reproducible to within about $5 \%$. Salt corrections were applied as per Hamilton (1971). Some samples of extremely hard and nonporous lithologies were powdered to more accurately determine grain densities. Compressional-wave velocities were determined using a Hamilton frame velocimeter, with an estimated accuracy of about $2 \%$ (Boyce, 1976). Residues from index properties measurements were tested for calcium carbonate content using a coulometer, with an estimated error of about $1 \%$.

Standard logging runs during Leg 129 included a quad-combination string (long-spaced sonic, dual-induction, natural spectral gamma, and high-temperature lithodensity tools) and a geochemical combination string (natural spectral gamma, induced spectral gamma, and aluminum clay tools). These tools all have different sampling intervals, depths of investigation, and sensitivities to hole conditions. Complete descriptions of the tools can be found in the Ocean Drilling Program Logging Manual (Borehole Research Group, 1990). Logs were recorded in all cases through as much open hole as was available. Because the logs were run last, often after many days of coring and drilling, deteriorating hole conditions allowed only parts of each hole to be logged (Lancelot, Larson et al., 1990).

Log records from the different strings run in the same hole were depth-shifted to match natural gamma readings, where possible. In Hole $801 \mathrm{~B}$, the lithodensity and natural gamma tools were run out of sequence, resulting in irradiation of the formation immediately before measurement of "natural" radiation levels. Depth-shifting in Hole $801 \mathrm{~B}$, therefore, required a more subjective matching of natural gamma and other tracks from the geochemical string and with physical-property records from the quad-combination string. Log depths were tied to core depths (that is, depth below the seafloor) based on the identification of the seafloor and/or the end of the pipe and the driller's depth records.

The caliper from the lithodensity tool was used to measure borehole size to identify washed-out zones and correct the responses of tools to borehole variations. Records from the long-spaced sonic tool were processed aboard ship to remove noise and unrealistic velocities caused by cycle skips (Lancelot, Larson et al., 1990). Data from the geochemical combination string were subjected to significant postcruise processing, as described in Hertzog et al. (1989) and Pratson et al. (this volume). The field data were first corrected for logging speed, pipe effects, and the presence of mud added to the borehole to maintain hole stability. Relative elemental yields were then determined for a maximum of nine elements. Total radioactivity and Th, $\mathrm{U}$, and $\mathrm{K}$ concentrations were calculated with data from the natural spectral gamma tool, and $\mathrm{Al}$ concentrations were calculated with data from the aluminum clay tool, with a correction applied for silicon interference. $\mathrm{Al}$ and $\mathrm{K}$ elemental yields were then normalized to allow for the calculation of elemental, dry-weight fractions. These fractions were, in turn, used to estimate dry-weight fractions of individual 
oxides. Comparison of geochemical log and laboratory data has often revealed accuracy for elements better than 3\% (van den Oord, 1990; Wentdlandt and Bhuyan, 1990; Cannon and Coates, 1990).

The geochemical logging tools were developed primarily for oil field applications. As such, the tools have generally been tested and calibrated within lithologies typical of these settings. For example, the conversions from elemental yields to oxide abundances are based on experimental data from "typical" sedimentary rocks (Pratson et al., this volume), which may not be typical of those materials logged during Leg 129. As elemental responses are not expected to be linear with concentration (Hertzog et al., 1989), the exotic nature of some Leg 129 lithologies adds significant uncertainty to the interpretations based on geochemical logging data. In addition, much of the geochemical log calibration and processing is proprietary, meaning that the exact procedures are not available to the scientific community.

Logging data collected on the Resolution were recorded every $0.15 \mathrm{~m}$ (6 in.). In order to directly compare log measurements from different strings, reduce the number of data points to a more manageable quantity, and allow for cross-plotting and ratioing, we passed the data through a 0.5 - $\mathrm{m}$ boxcar-averaging filter, with final depths chosen at regular $0.5 \mathrm{~m}$ intervals relative to the seafloor (i.e., 55.0, 55.5, $60.0, \ldots \mathrm{m}$ below seafloor [mbsf]). All logs presented in this paper have been filtered using the same scheme; examination of the final curves suggests that significant character remains after filtering.

\section{Physical Properties Rebound Corrections}

In the following sections, we have grouped data by lithotype and plotted all properties as a function of depth to examine compactional influences on physical properties. Compaction is a function of time, not just depth (e.g., Busch, 1989), but this simple approach allows elucidation of several important relationships. Figure 2 reveals that only the clay and claystone samples collected during Leg 129 display a significant compaction with depth. In particular, the chert, limestone, porcellanite, radiolarite, and chalk samples display no coherent variations in porosity with depth. Several chert samples collected from above $100 \mathrm{mbsf}$ are somewhat higher in porosity (and correspondingly lower in density) than those found below $300 \mathrm{mbsf}$, but within each group there is no strong trend. Sandstone and tuff samples display a slight decrease in porosity with depth and siltstone samples reflect a significantly greater compactional trend, but clay and claystone samples fall squarely between the pelagic clay and terrigenous sediment curves defined by Hamilton (1976). This finding suggests that, to a first order, only the index properties of clay and claystone samples need be corrected for rebound due to removal from in-situ conditions. Some caution must be used in making this interpretation, as there may have been insufficient time for the samples to rebound fully between collection and testing. For this reason, we have chosen to apply the smaller of the rebound corrections suggested by Hamilton (1976) for clay-rich sediments, that for terrigenous clay (Fig. 2A). No porosity correction has been applied to data from chalk samples, mainly because these data do not display a coherent trend with depth (Fig. 2B). In addition, within an appropriate range of porosities the acoustic properties of pelagic carbonate sediments may be somewhat less sensitive to interparticle porosity than they are to intraparticle porosity, changes in which do not depend directly on burial and compaction (e.g., Fulthorpe et al., 1989).

Cross-plots of bulk density and velocity vs. porosity of clay and silt-rich sediments (Fig. 3A) reveal consistent relationships between these properties (as is to be expected where grain density is relatively constant). We have used these relationships to calculate rebound corrections for bulk density and compressional-wave velocity by assuming that a change in porosity associated with rebound simply moves the other properties along the appropriate, best-fit curves in Figure 3. Plots of corrected bulk density and compressional-wave velocity vs. depth (Fig. 4) also illustrate the relative insensitivity of all
A

Porosity (\%)

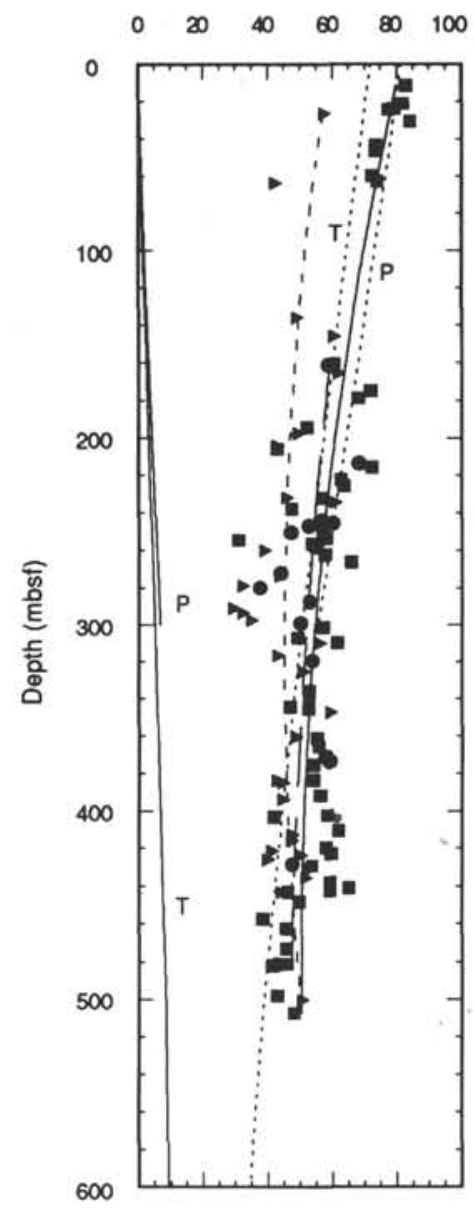

B Porosity (\%)

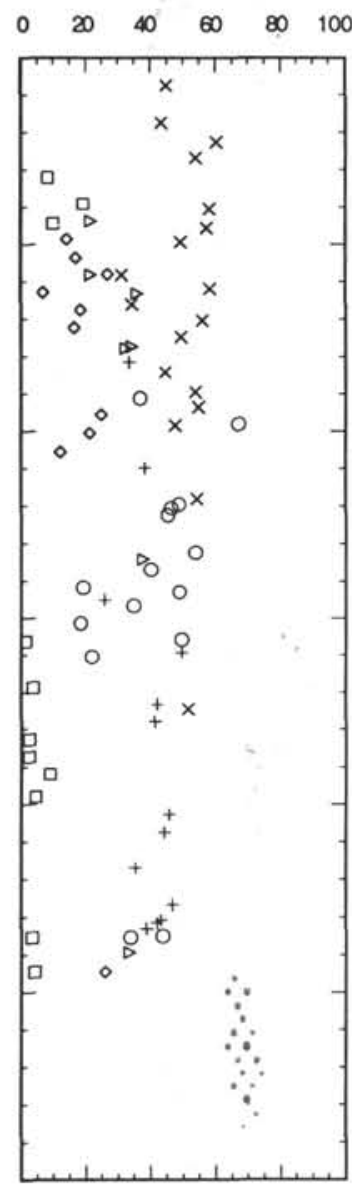

Figure 2. Uncorrected porosity vs, depth for all physical-properties samples collected during Leg 129. Sediment assignments are based on observations by shipboard scientists (Lancelot, Larson, et al., 1990) A. Solid squares: claystone and pelagic clay; solid circles: siltstone; solid triangles: sandstone. The dotted curves on the right side of the figure were determined by Hamilton (1976) for "typical" pelagic clay (P) and terrigenous clay (T) and are second-order polynomials. The best-fit solid curve that passes through data from the Leg 129 pelagic clay and claystone samples falls between the two Hamilton curves, suggesting that these sediments follow similar compactional trends. Best-fit curves for the siltstone samples (long dashes) and sandstone samples (short dashes) show much smaller compactional trends. The solid curves on the left side of the figure illustrate Hamilton's (1976) rebound corrections for pelagic clay $(\mathrm{P})$ and terrigenous clay $(\mathrm{T})$. All Leg 129 clay samples were rebound-corrected using the more conservative, terrigenous curve. B. The remaining sediment types characterized by porosity measurements during Leg 129 reveal no consistent compactional trends, suggesting that rebound corrections are unnecessary. Open squares: chert; open circles: chalk; open diamonds: siliceous limestone, open triangles: porcellanite; pluses: radiolarite; $x$ 's: tuff.

lithologies except clay and claystone to the mechanical consolidation associated with burial. This observation could mean that the materials that formed the other lithologies did not experience mechanical compaction, or that mechanical effects have been overprinted by later diagenesis.

\section{LOGGING AND LABORATORY PHYSICAL-PROPERTIES DATA}

Log and laboratory measurements are directly compared in Figures $5-7$, following application of the corrections discussed pre- 

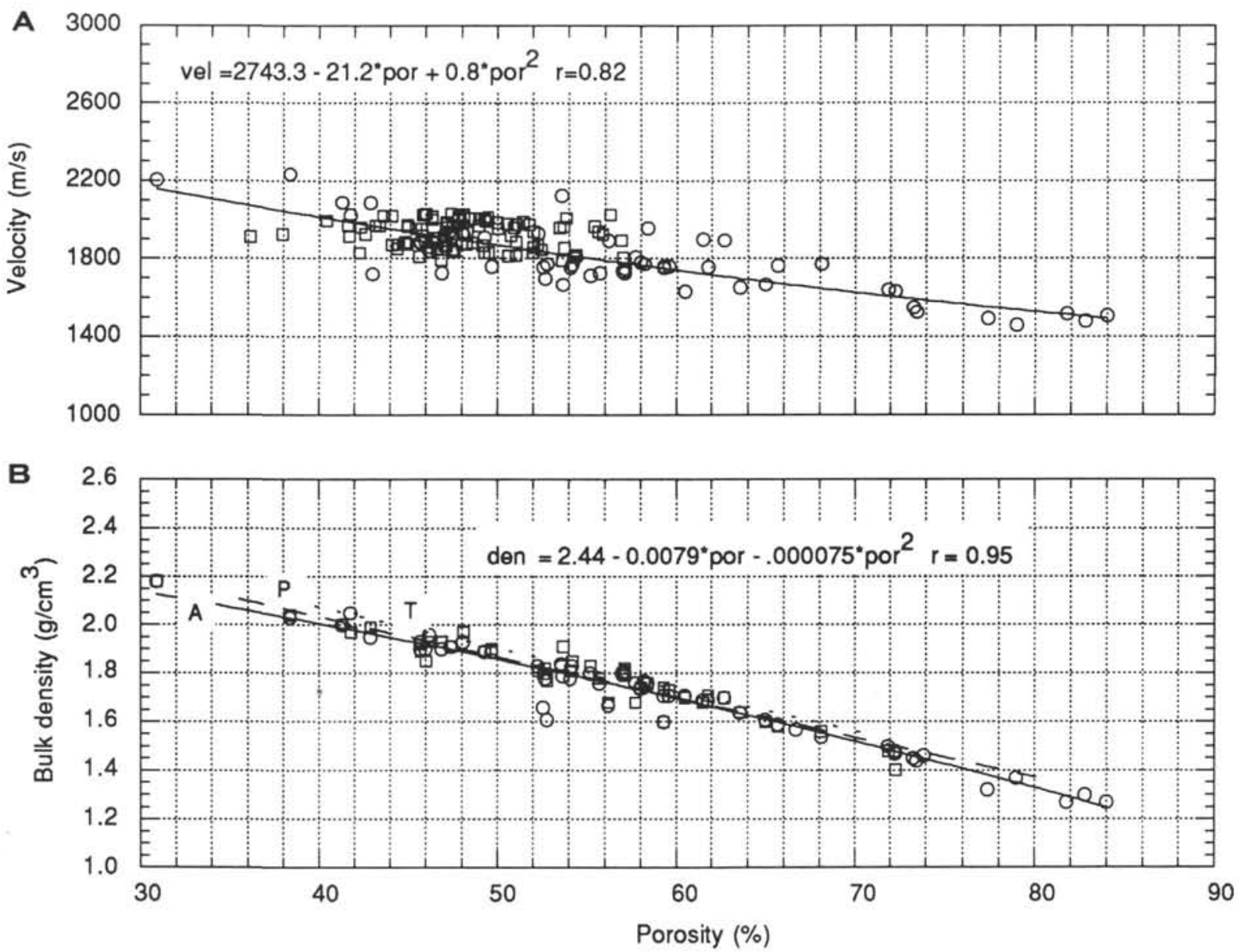

Figure 3. Cross-plots of the physical properties of pelagic clay and claystone samples. The best-fit curves in these figures were used to apply rebound corrections to shipboard data. A. Vertical compressional-wave velocity vs. porosity. Circles are laboratory data from all sites; squares are log data within clay-rich zones from Site 800 only. The presence of intervals composed mainly of clay was not apparent from the logs at Sites 801 and 802. Log velocities were measured directly, but log porosities were determined from the lithodensity log and a synthetic grain density log derived from the lithologic inversion described elsewhere in this paper. The borehole and laboratory trends agree. The solid line is a best-fit, second-order polynomial through the laboratory data only. B. Bulk density vs. porosity. Circles are measurements made using standard gravimetric methods; squares are from two-minute GRAPE measurements (Lancelot, Larson et al., 1990). The solid line is a best-fit, second-order polynomial through all data (A). The dashed line is the expected relationship from trends listed in Hamilton (1976) for pelagic clay $(\mathrm{P})$, whereas the dotted line is a similar relationship for terrigenous clay $(\mathrm{T})$.

viously. Depth errors may have been introduced in core-log depth correlations. Many errors are introduced as a result of differential drill-pipe and wireline stretch and heave. In addition, all recovered core has been pushed to the top of the cored interval for archival purposes, as is standard ODP procedure.

We have confidence in the overall quality of the density and velocity logs in Hole $800 \mathrm{~A}$ because of the strong, nearly peak-forpeak, correlation between the two. There is also excellent agreement between laboratory and borehole density measurements within the interval of 220-280 mbsf (mainly Unit IV, redeposited volcaniclastics). The agreement between the measurements at 160-220 mbsf is also surprisingly good, considering the extremely poor recovery and biased sampling in this section. Significantly higher laboratory density measurements between 40 and 160 mbsf are not surprising considering the preferential core recovery in the chert and limestone of lithologic Units II and III.

Velocity measurements from Hole $800 \mathrm{~A}$ follow similar trends, with excellent agreement between 220 and $260 \mathrm{mbsf}$, and significantly poorer agreement at lesser depths. It is not immediately apparent what happened below 150 mbsf that allowed the two data sets to match so closely, but this is the approximate depth below which claystone and chalk appear in cores within the chert and limestone of lithologic Unit III. It may be that these constituents were also present in the shallower portions of the section, but were too soft and unlithified to allow recovery.

We inverted the medium-depth resistivity log derived from the dual-induction tool to look at in-situ porosity trends, with poor results. The empirical Archie (1942) relationship for clean quartz sandstone is known to break down in unlithified to semilithified, high-porosity materials, and when clay content is greater than a few percent (e.g., Waxman and Smits, 1968; Clavier et al., 1977) because the measured resistivity includes contributions from both free water in pores and bound water on clay minerals. Although the absolute correlation between laboratory porosities and $\log$ porosities determined with Archie's Law is poor, there are zones within which the two curves follow similar trends; these are the same zones over which there is a good correlation between shipboard and log density and velocity data.

Also shown in Figure 5 (and in Figs. 6 and 7 for Sites 801 and 802 , respectively) is a synthetic porosity log calculated from the borehole bulk density curve, an assumed pore-fluid density of 1.050 $\mathrm{g} / \mathrm{cm}^{3}$ (appropriate for seawater at $6000 \mathrm{~m}$ water depth; Neumann and Pierson, 1966), and an average grain density based on the weight per- 


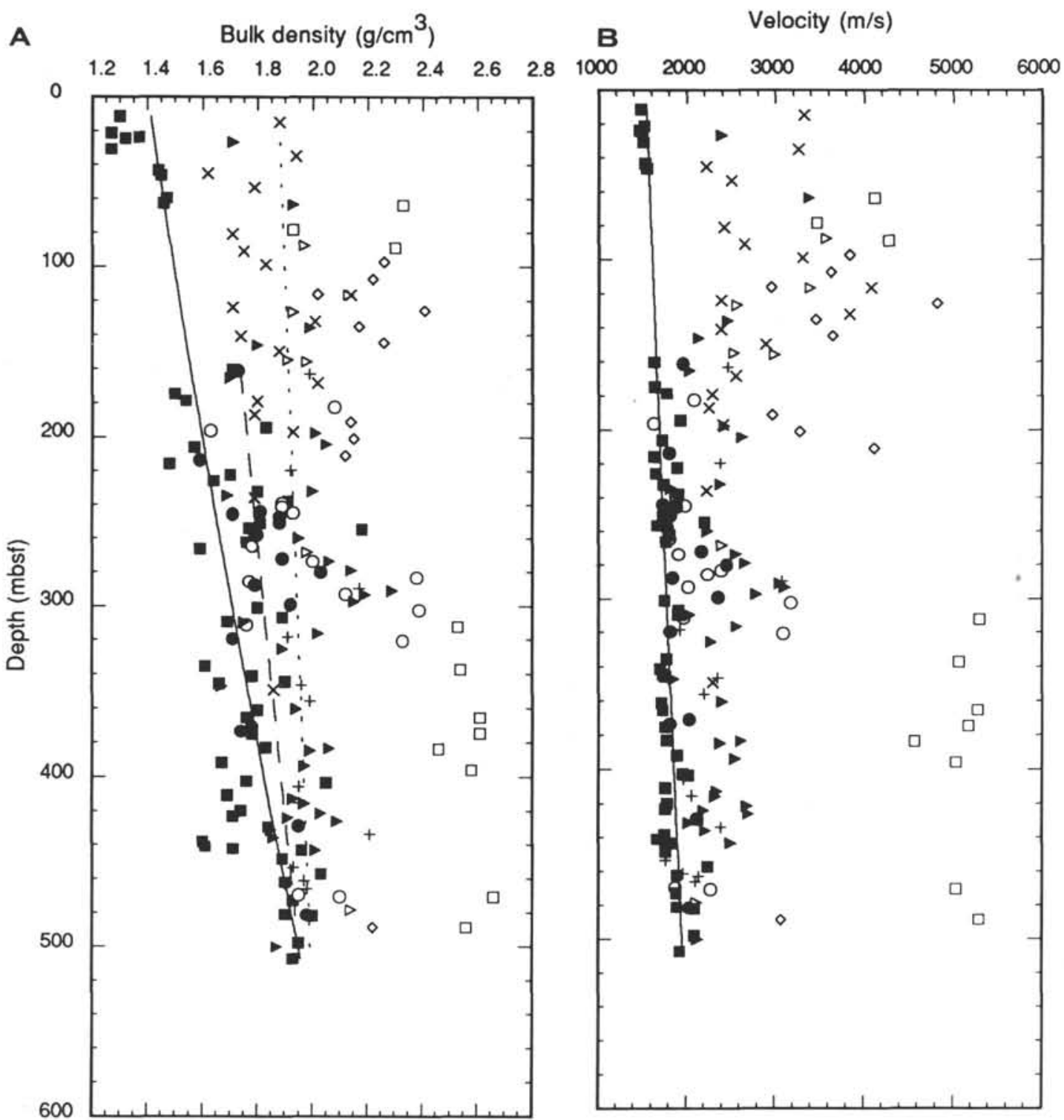

Figure 4. Rebound-corrected physical properties vs. depth from Leg 129. The symbols are the same as in Figure 2. The solid lines illustrate trends in the pelagic clay and claystone data. A. Bulk density. B. Compressional-wave velocity.

centages of individual lithologies determined with the inversion procedure described later in this paper. The porosity data show trends corresponding to those of the other physical-properties data; the variable goodness of fit of the laboratory porosity data to the synthetic porosity log support the inference that the laboratory data are representative only within zones over which recovery was relatively high.

At Site 801, the section from about 190 to 270 mbsf displays remarkable agreement between borehole and corrected laboratory physical-properties data (Fig. 6). Again, the materials that dominate this interval are redeposited volcaniclastic sediments. Chert- and radiolarite-rich sections reveal less consistent trends. The fit between the lab and borehole data is best overall in Hole 802A (Fig. 7). There is general agreement throughout the logged section, with an excellent match below about 200 mbsf. The logged interval in Hole $802 \mathrm{~A}$ is composed almost entirely of volcaniclastic tuff, claystone, and chalk, which seem to have allowed for the most representative core sampling of the drilled formation, despite the relatively low recovery.

The corrected laboratory data provide a means to check the consistency of borehole measurements, particularly within zones of good recovery where we have high confidence that the core is representative of the drilled section. In all cases where recovery was good $(>60 \%-70 \%)$ the match between physical-properties measurements and corresponding logs is excellent. If borehole conditions were sufficiently good for the lithodensity tool, which is highly sensitive to borehole irregularities, conditions within the same zones should have been good for other logs as well. Within identifiable zones in these intervals that contain a single lithology, individual properties or characteristics of that lithology can be determined. If a zone assumed to contain a single lithology actually contains a mixture of several lithologies, characterization of any one will be impossible without an a priori estimate of the relative proportions and properties of the other constituents.

\section{Mean Properties}

The consistency of physical properties as a function of lithology (rather than depth or degree of compaction) is evident when individual measurements are averaged using samples that appeared to be 


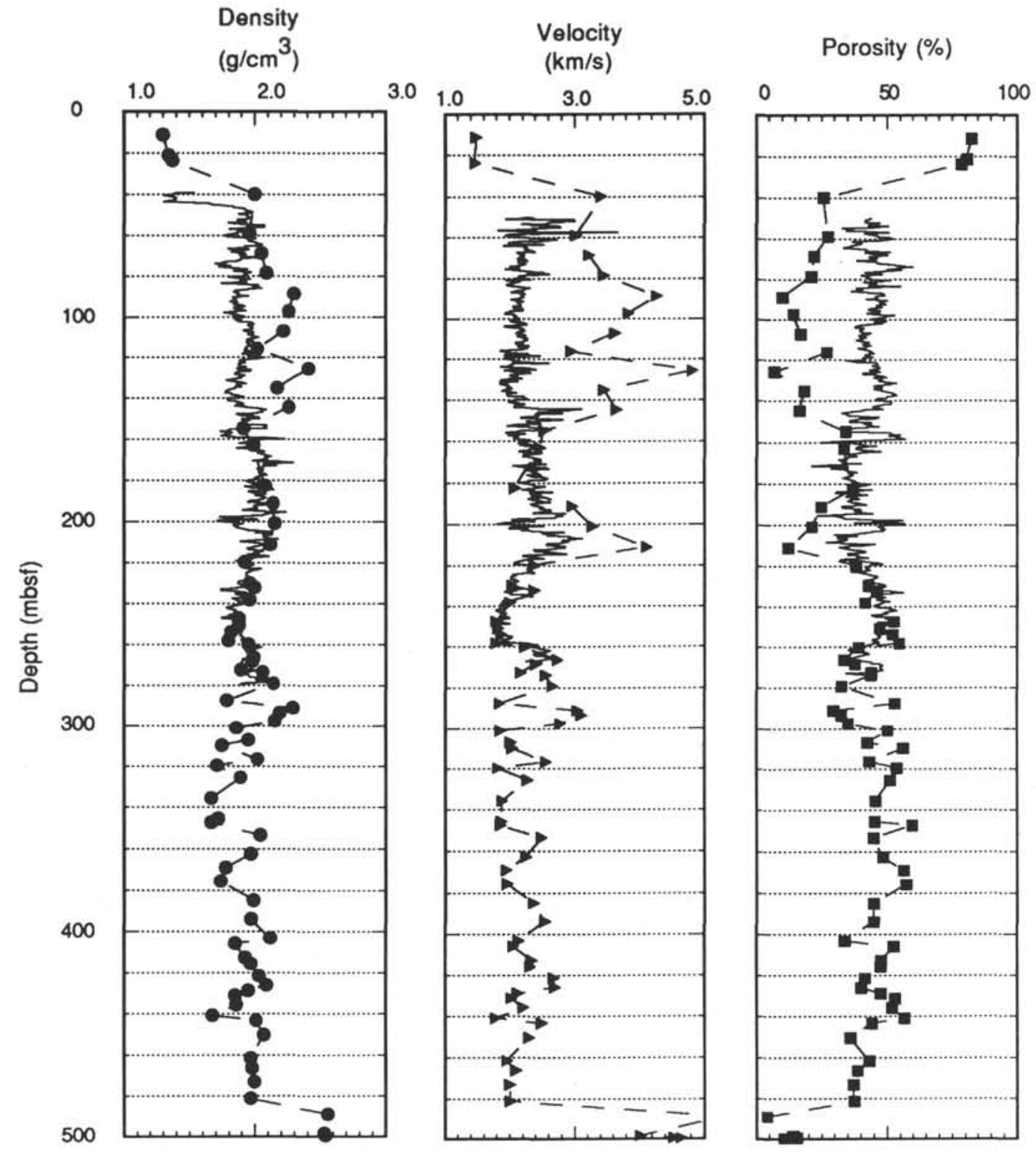

Figure 5. Physical properties from shipboard (symbols and dashed lines) and log (solid lines) measurements from Site 800. Log data have been smoothed using a $0.5-\mathrm{m}$ boxcar filter. Shipboard measurements of clay samples have been rebound corrected. No porosity logs were run during Leg 129; a synthetic porosity log was generated using the lithodensity log and an average grain density for each depth based on the lithologic inversion presented later in this paper.

composed of mainly one lithology (Fig. 8). At either end of the physicalproperties spectrum are the chert and pelagic clay samples. The differences between these materials and all others are large enough to make a reasonable lithologic identification possible, based on only one or two measurements. For example, the chert samples had significantly higher velocitiesthan all other materials (about $4.8 \mathrm{~km} / \mathrm{s}$ ), and the average would be even higher (and the standard deviation lower) if the three shallow, porous chert samples from Sites 800 and 801 were not included. Partly because of scatter in the data, as evident from the large standard deviations associated with each mean, several of the lithotypes seem to be indistinguishable based only on their physical properties. The mean velocities, densities, and porosities for radiolarite and chalk are almost identical, although their chemical and textural differences are sufficient to distinguish them in hand sample.

Porcellanite and the sandy Miocene tuff (found only at Site 802) have similar mean velocities; it is simple to distinguish the two because they have sufficiently different porosities and bulk and grain densities (Fig. 8).
The lower grain density of the sandy tuff from Site 802 compared with the sandy portions of the Cretaceous turbidites from Sites 800 and 801 may reflect the larger feldspar and glass content of the former. Several of the differences in classification directly reflect properties, or degree of diagenesis, rather than initial composition. For example, the distinction between chert and porcellanite made by shipboard sedimentologists was largely one of hardness, although the major control on these properties may be the initial silica/clay ratio (Lancelot, Larson et al., 1990). Radiolarite and chert may similarly be at ends of a diagenetic spectrum, which depends largely on the clay content of the sediment, as described by Behl et al. (this volume).

\section{Comparison of Borehole, Laboratory, and Seismic Interval Velocities}

Examination of sonic logs from Leg 129 provides strong evidence that we do not have a good understanding of the composition of the 


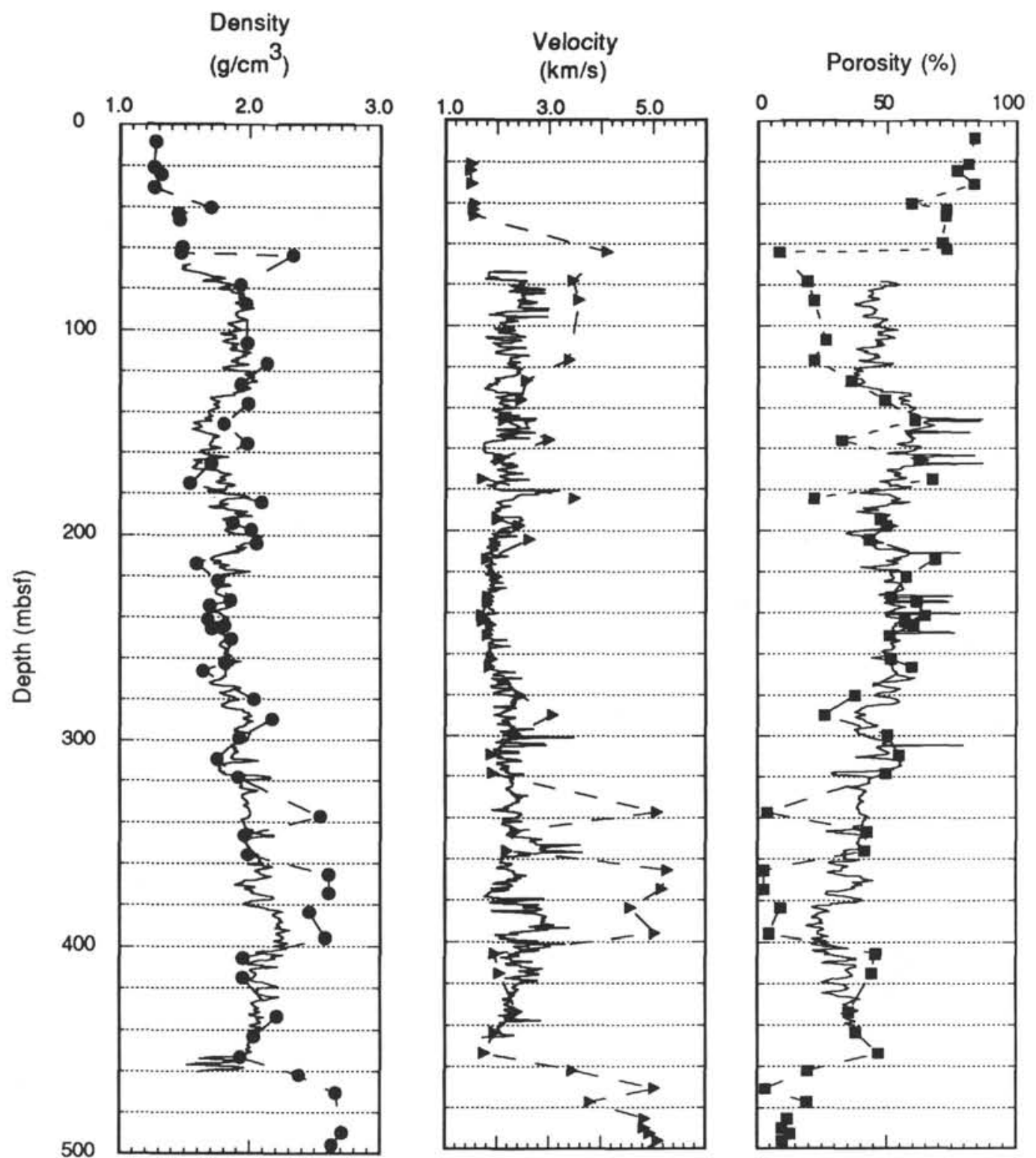

Figure 6. Physical properties from shipboard (symbols and dashed lines) and log (solid lines) measurements from Site 801; curves and symbols are as in Figure 5.

sedimentary section drilled at the three sites. Figure 9 illustrates a comparison of interval slowness estimated from the correlation of seismic reflectors with lithologic boundaries, and slowness determined using the long-spaced sonic tool. Over complete logged intervals, the sonic slowness is within one standard deviation of the inferred interval slowness. The weighted fit for Sites 800 and 802 is actually quite good, and the fit for Site 801 somewhat less so. When the individual seismic intervals are examined, however, the match is less assuring. Zones predicted to have low slowness (high velocities) from seismic picks have higher sonic-tool slowness (lower velocities), whereas other zones predicted from the seismic picks to have high slowness (low velocities) have lower sonic-tool slowness (higher velocities). It is not expected that the seismic and sonic data will be a perfect match, particularly because only portions of some seismic intervals were logged; a good match of seismic and sonic velocities within these intervals would require that average velocities apply across each. Velocities of complete seismic intervals over which the sonic tool was run should match, however.
The interval velocities reported by the Shipboard Scientific Party $(1990 \mathrm{a}, \mathrm{c})$ for Sites 800 and 802 were estimated from synthetic seismograms derived from logged velocity and density measurements, whereas the interval velocities for Site 801 were estimated without the guidance of log-generated synthetic seismograms. The detail presented for the interval velocities (Shipboard Scientific Party, 1990a, figure 42; Shipboard Scientific Party, 1990b, figure 57; Shipboard Scientific Party, 1990c, figure 58) was poorly constrained, particularly at Site 801 , although there are several correlatable seismic and lithologic horizons that should provide a reasonable estimate for average sediment velocities.

There appears to be a good correlation between seismic reflections and cored lithologies at the following sub-seafloor boundaries: the top of Upper Cretaceous chert and porcellanite units at Sites 800 and 801 (Unit II in both cases); the top of a massive chert bed at the base of, or bounding, Unit III at Site 801; the top of the first abundant chert interval within the chalky part of Unit III at Site 802; and the top of massive igneous units at all three sites (Jurassic igneous basement at Site 801; 

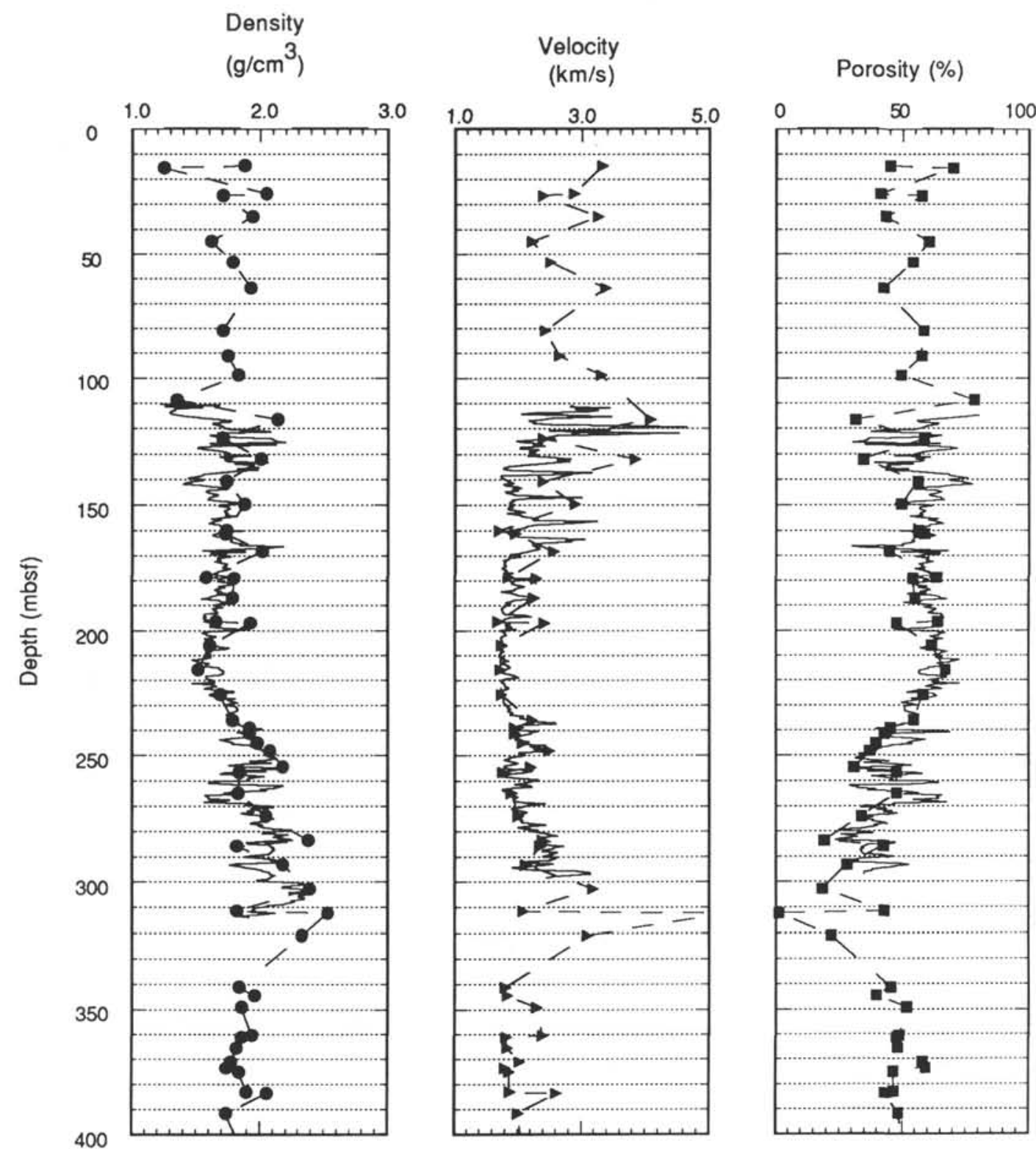

Figure 7. Physical properties from shipboard (symbols and dashed lines) and log (solid lines) measurements from Site 802; curves and symbols are as in Figure 5.

mid-Cretaceous sills at Site 800; mid-Cretaceous flows at Site 802). Combined with a good reflector at the seafloor, these correlations suggest average velocities for the sedimentary sections of approximately $2.0 \mathrm{~km} / \mathrm{s}$ at Sites 800 and 801 and $1.9 \mathrm{~km} / \mathrm{s}$ at Site 802 (Abrams et al., this volume). These interval velocities are consistently lower than the sonic-log velocities determined from averaging travel times over the logged intervals (Sites 800 and $801: 2.2 \mathrm{~km} / \mathrm{s} ;$ Site $802: 2.1 \mathrm{~km} / \mathrm{s}$ ). The sonic-log velocities covary consistently with the resistivity, gamma-ray, and bulk-density logging data, which indicates that at least the relative changes in logged velocities are correct. It is these changes in velocities that provide a necessary discriminant for the inversion exercise that follows.

\section{Comparison of Log and Laboratory Geochemical Data}

Figures 10-12 illustrate processed geochemical log data plotted with laboratory data from the three sites. Within the chert-rich intervals, laboratory silica contents tend to exceed those calculated from log measurements, which is not surprising as cherty lithologies tended to be
(1) preferentially recovered, and (2) preferentially sampled by chert specialists who provided most of the data over these intervals (Behl, this volume; Karl and Karpoff, this volume). The Site 800 laboratory data for the other major oxides used in this study match the log-derived oxides well (Fig. 10). At Site 801, log-derived silica oxide contents are again lower than those determined in the laboratory, particularly in the uppermost volcaniclastic turbidites of lithologic Unit III (Fig. 11). The lab data from this interval also include preferentially sampled chert and porcellanite. These samples also yielded lower aluminum and iron oxide percentages than measured with logs, and calcium contents are low throughout the logged interval (Fig. 11). The match between log- and lab-derived oxide contents appears to be fair to good at Site 802, where dominantly volcaniclastic tuff and chalk were logged (Fig. 12). This interval displays the widest range in variations of all oxides, making a realistic evaluation of the match between $\log$ and lab data difficult (particularly considering the lingering questions concerning core-log depth shifting). Some of the logged oxide contents appear to be unrealistically extreme at Site 802 (particularly silica and iron), which may 

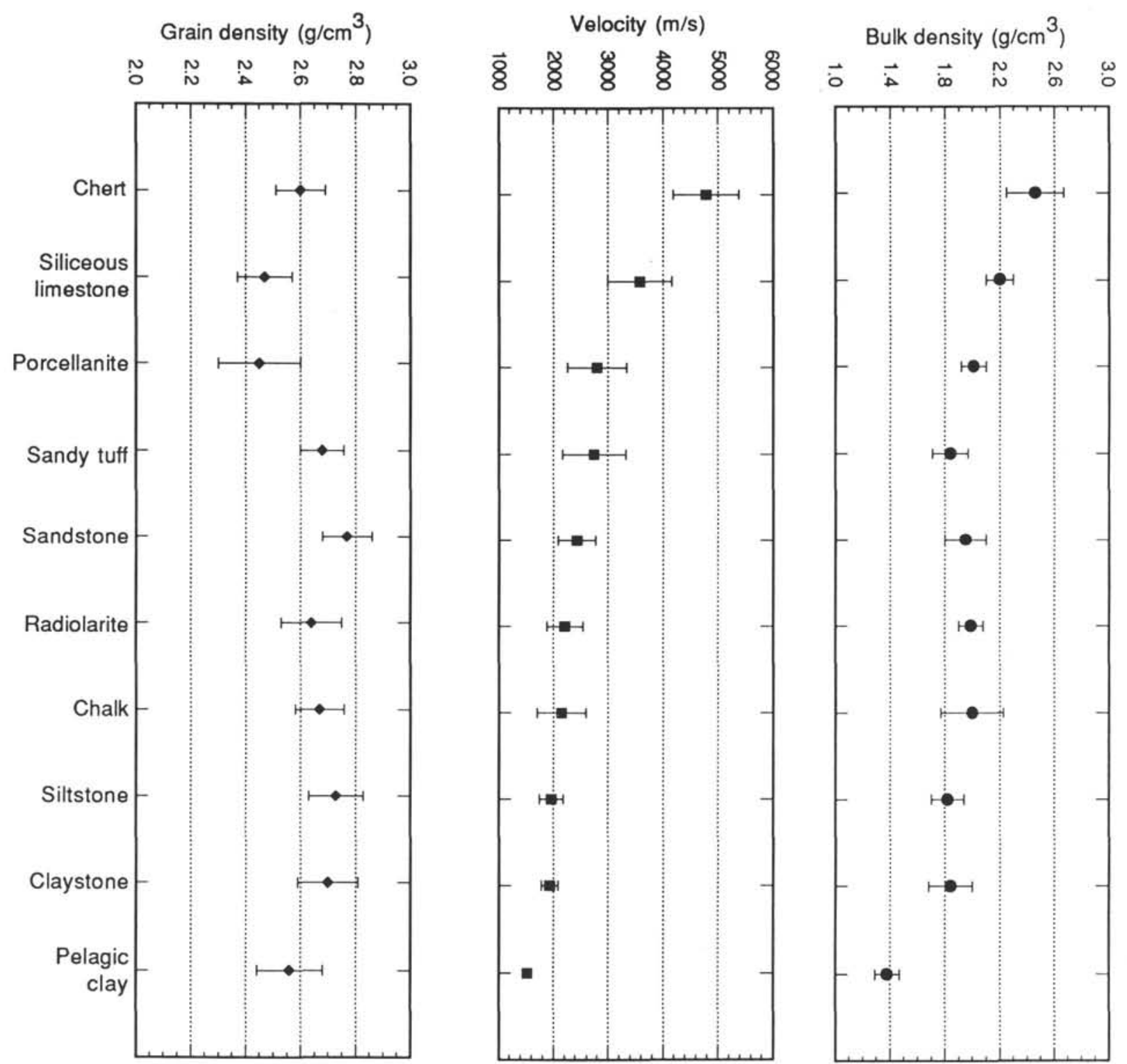

Figure 8. Average bulk density, vertical compressional-wave velocity, and grain density values for each of the 10 primary lithologies identified during Leg 129, as determined with shipboard measurements. Bars indicate one standard deviation. Data from clay samples have been rebound corrected.

reflect the use of the geochemical logging tool and standard processing outside the normally calibrated range.

\section{INVERSION OF LOGS FOR LITHOLOGY}

Since its introduction, the geochemical logging tool has been used to determine quantitative mineral assemblages, usually through inversion of calculated element and oxide abundances (e.g., Harvey et al., 1990). There are many techniques available to complete this inversion, and each has benefits and drawbacks. We have used selected physical properties logs in combination with calculated oxide percentages and several limiting assumptions to estimate the abundances of fixed lithotypes throughout the logged intervals of Sites 800,801 , and 802 .

As a first step in this exercise, we have defined a series of idealized "lithotypes" that have end-member compositions and properties. This approach contrasts with standard geochemical log inversions for mineralogy (e.g, van den Oord, 1990; Wentdlandt and Bhuyan, 1990; Pratson et al., this volume). We did not feel that we had sufficient data (either laboratory or borehole) or sufficient confidence in the borehole data (particularly at Site 802) to constrain the vast number of mineralogies apparent from $x$-ray diffraction analysis, and hand-sample and thin-section examination (Lancelot, Larson et al., 1990). In addition, our primary interest was in determining the relative proportions of lithologies present in the chert-, radiolarite-, and limestone-rich intervals. Following completion of this first-order analysis, a more detailed mineralogical analysis could focus on the mineralogies within isolated intervals.

The use of linear inversion techniques is detailed elsewhere (Harvey et al., 1990); only a brief overview is presented here. We assume that the instrument response for each measurement used in the analysis varies in direct response to the proportion of each constituent, according to the following system of equations, expressed in matrix form: 


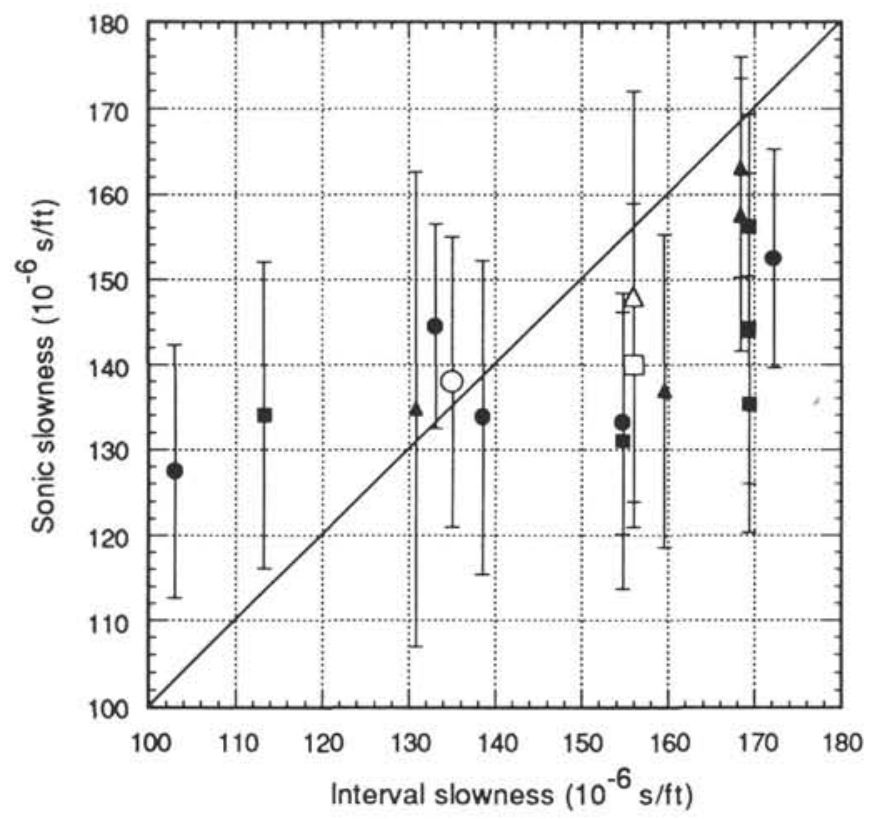

Figure 9. Sonic slowness for individual logged intervals vs. interval slowness, based on picks from synthetic seismograms made during Leg 129 (Lancelot, Larson, et al., 1990). Circles: Site 800; squares: Site 801; triangles: Site 802. Sonic slowness was determined by averaging measurements from the longspaced sonic tool; bars indicate one standard deviation. Slowness was used in this study, rather than velocity, because the former is believed to vary more linearly as a function of lithology, as discussed in the text. Solid symbols indicate the slowness of individual intervals, whereas the large, open symbols indicate average values for entire logged sections. A good match between determinations made with the different methods would result in points that fall on the solid line, which has a slope of 1 . Relative to sonic-log determinations, interval picks overestimated velocities for high-velocity (low-slowness) materials and underestimated velocities for low-velocity (high-slowness) materials.

$$
\left[\begin{array}{cccc}
X_{1,1} & X_{1,2} & \cdots & X_{1, m} \\
X_{2,1} & X_{2,2} & \cdots & X_{2, m} \\
\cdot & \cdot & & \cdot \\
\cdot & \cdot & \cdots & \cdot \\
\cdot & \cdot & & \cdot \\
1.0 & 1.0 & \cdots & 1.0
\end{array}\right] \times\left[\begin{array}{c}
p_{1} \\
p_{2} \\
\cdot \\
\cdot \\
p_{n}
\end{array}\right]=\left[\begin{array}{c}
c_{1} \\
c_{2} \\
\cdot \\
\cdot \\
1.0
\end{array}\right]
$$

where $n$ is the number of components in the natural system, $p_{n}$ is the proportion of each component, $m$ is the number of logs, $X_{n, m}$ is the response of each log to each component, and $c_{\mathrm{n}}$ is the actual log signal. In this exactly-determined system, the matrix equation can be expressed as $\boldsymbol{X} \times \boldsymbol{p}=\boldsymbol{C}$, where the matrix $\boldsymbol{p}$ is the desired solution, and is easily determined through inversion.

We have elected to use a simple error minimization model based on an over-determined system of equations to estimate the abundances of individual rock types. In an over-determined system, the inverted matrix equation is $\boldsymbol{p}=\left(\boldsymbol{X}^{T} \boldsymbol{X}\right)^{-1} \boldsymbol{X} \boldsymbol{c}$. In this formulation, there must be at least as many logs as there are components to be identified. The system will then be at least slightly over-determined as the unity relation (requiring that the decimal fractions of all final components must add up to one) provides one more constraint. In practice, it is desirable that there be at least several more logs than components, particularly in cases where the accuracy of individual logs or the consistency of chemical compositions of the individual components is in question.

Weights can be assigned to each log based on the expected accuracy and reliability of the signal, as well as the significance of the signal in differentiating lithotypes. In equation (2), these weights would be expressed as proportional factors against which the total signals $(c)$ are multiplied. When weights are included in an over-determined system, the proportions of individual components are determined through solution of the following matrix equation: $p=\left(X^{T} W\right.$ $\boldsymbol{X})^{-1} \boldsymbol{X}^{T} \boldsymbol{W} \boldsymbol{c}$, where $\boldsymbol{W}$ is a diagonal matrix containing the elements of the weight vector (Harvey et al., 1990).

In order for the transform to be stable, there must be at least one $\log$ that clearly discriminates each component. For example, the bulk density $\log$ is useful for separating chert and clay components at Leg 129 sites, based on the widely different responses each of these lithologies typically provides (Fig. 8). If one part of the sedimentary section is assumed to be composed only of chert and clay, then only a single, good-quality density log is needed to assign the relative proportion of each present over that interval. The same log would be useless for separating radiolarite and chalk components, however, because of their similar responses (Fig. 8). A better discriminator in this latter case might be $\mathrm{CaO}$ content, as estimated from the geochemical tool.

As more components are added to the system, additional discriminatory logs are needed. A system composed entirely of chert, limestone, and clay would, at first, seem to require only two logs, perhaps density and sonic. All three lithologies have distinct densities and travel times (Fig. 8), suggesting that an exactly determined system of equations (three lithologies and three equations, two logs plus the unity relation) should be adequate to estimate the relative proportion of each component. The hitch in this case is that one of the three components (limestone) has properties that are intermediate compared to both properties of the other two components. Chert has the highest density and velocity, and clay the lowest of each. Thus, a linear system of chert, limestone, and clay, which includes only two physical indicators, is actually underdetermined in a strict sense because the inverse problem is still underconstrained (i.e., an inversion using only these two logs does not allow for discrimination between a mixture of chert and clay from pure limestone). Adding an additional discriminator, such as calcium content, would allow the limestone component to stand out more clearly.

We have modified the basic approach to log inversion in several ways. Most importantly, we have elected to invert for idealized "lithotypes" rather than individual mineral components. This is equivalent in some ways to defining a series of electrofacies (Serra, 1986). We have taken this approach because it allows us to emphasize differences in density and velocity between distinct lithologies without introducing errors due to poorly understood, often empirical, mixing transforms. Standard chemical distinctions commonly used for mineralogical inversion are also used in this study, as individual lithotypes are assumed to have distinct mineralogical assemblages. We feel that this approach is necessary because we were unable to identify zones of truly pure mineralogy in the Leg 129 sediments at a scale of thickness and accuracy suitable for $\log$ calibration, whereas there are many samples and zones that are characterized by individual lithologies. The downside to inverting for lithotype, rather than mineralogy, is that the former includes an implicit interpretation with respect to the mineralogical composition of individual units. We feel this is a fair compromise, because the overriding assumption in any inversion is that the composition of possible components (be these lithological or mineralogical) is known to be from a finite list that is selected prior to the computation. This assumption introduces the greatest uncertainty in the calculations. At best, this analysis will result in an overall composition that is reasonable within the uncertainty of the measurements. This composition still must be justified on additional geological or geophysical grounds before it can be accepted.

\section{Characterization of Lithotypes}

In order to generate statistically meaningful results from the inversion of logging data, it is necessary to reduce the number of lithological components to as few end-member compositions as possible. A plot of $\mathrm{x}$-ray diffraction data from whole-rock samples collected from Sites 800,801 and 802 (Fig. 13; Behl, this volume) suggested the 

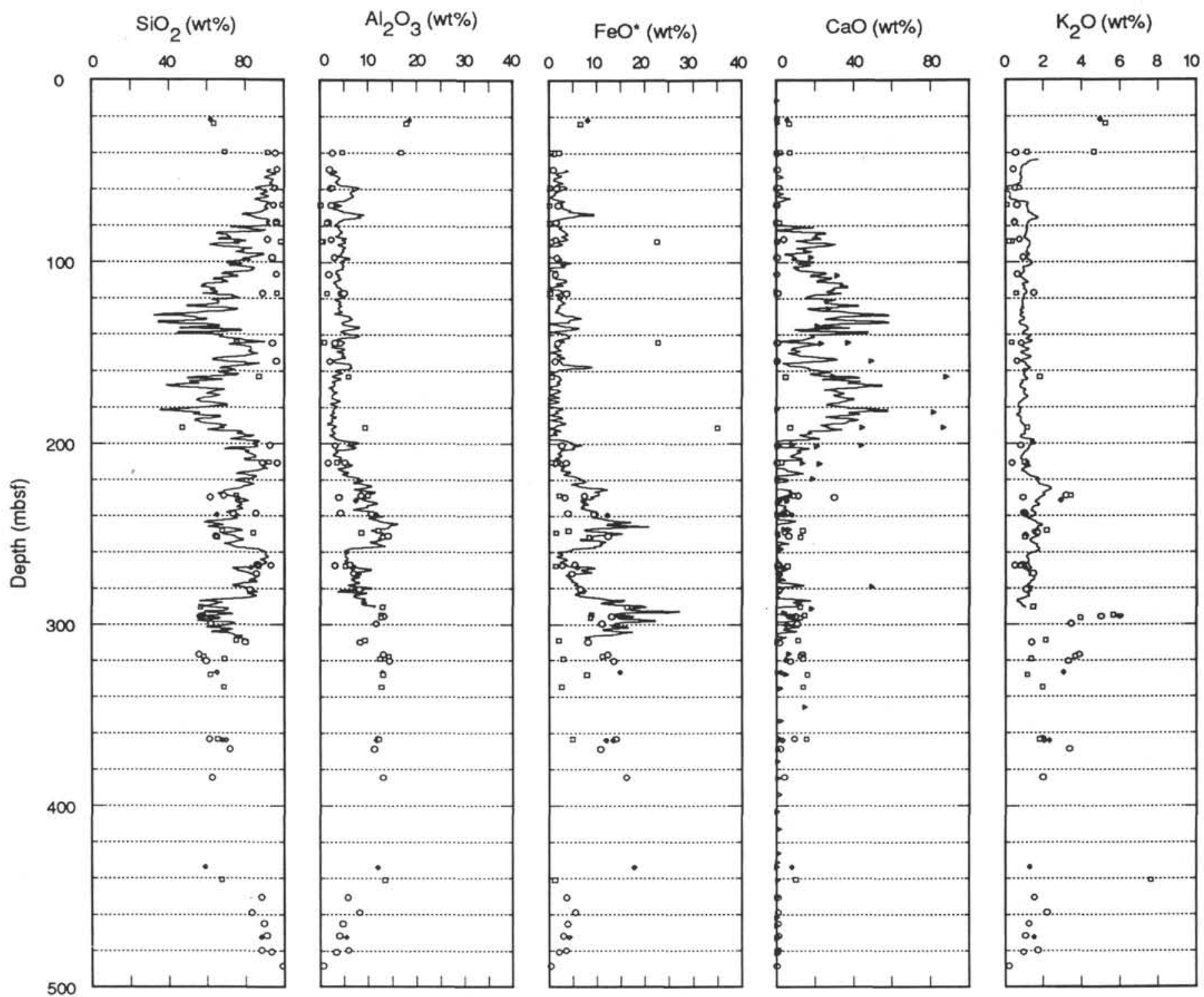

Figure 10. Normalized oxide contents of Site 800 sediments, from logs and laboratory determinations. Laboratory data are from Karl and Karpoff (this volume): circles; France-Lanord et al. (this volume): diamonds; Karpoff (this volume) and Karpoff et al. (this volume): squares; and Shipboard Scientific Party (1990a): triangles. The borehole data have been smoothed with a 0.5 -m boxcar filter. Geochemical log processing is described briefly in the text and in more detail elsewhere (Hertzog et al., 1989; Pratson et al., this volume).

approach we used to characterize sediments drilled during Leg 129. For example, chert and chalk are obvious end members, composed primarily of silica and calcium carbonate, respectively. We have included a third possible end member, clay + zeolites, which allows the inclusion of radiolarite, porcellanite, and siliceous limestone in the system, as all three fall between the three extremes on a ternary diagram (Fig. 13). The same relationships roughly hold for the geophysical properties, with radiolarite, porcellanite, and siliceous limestone falling between the chert, chalk and clay + zeolites extremes.

With this scheme, radiolarite and porcellanite may be considered "clay-chert mixtures," both in terms of their geochemical composition and geophysical properties. Similarly, siliceous limestone could be called a "chalk-chert mixture," as these samples have velocities, densities, and silica and calcium contents falling between the two compositional extremes. We learned early on in this study that the inclusion of intermediate lithotypes introduces instability in the inversion of logging data. We started our analyses with 10 lithotypes, testing all possible combinations of seven or fewer for each logging depth, before settling finally on these five extreme lithotypes: chert, chalk, pelagic clay, clay/siltstone, and sandstone/tuff.

These idealized lithotypes are assumed to have a narrow range of properties and compositions, and should not be confused with the more rigorously defined lithologies identified during Leg 129. For example, the lithotype "clay/siltstone" is used here to define a rock type that shares affinities with materials labeled as claystone and siltstone during the cruise. These materials have moderate velocities, densities, and silica contents, low calcium contents, and moderate-tohigh aluminum, iron, and potassium contents. In fact, these materials are generally composed of a mixture of various amounts of clay (mainly illite, smectite, and mixed-layer), feldspar, quartz, zeolite, mica, and glass shards (Lancelot, Larson et al., 1990). Similarly, the "chalk" lithotype has been idealized to be dominantly calcium carbonate, with some silica and traces of other oxides. The "chert" lithotype is assumed to be mainly silica, with traces of other oxides plus the highest densities and velocities of all sedimentary materials through which logs were collected. The "pelagic clay" lithotype has 

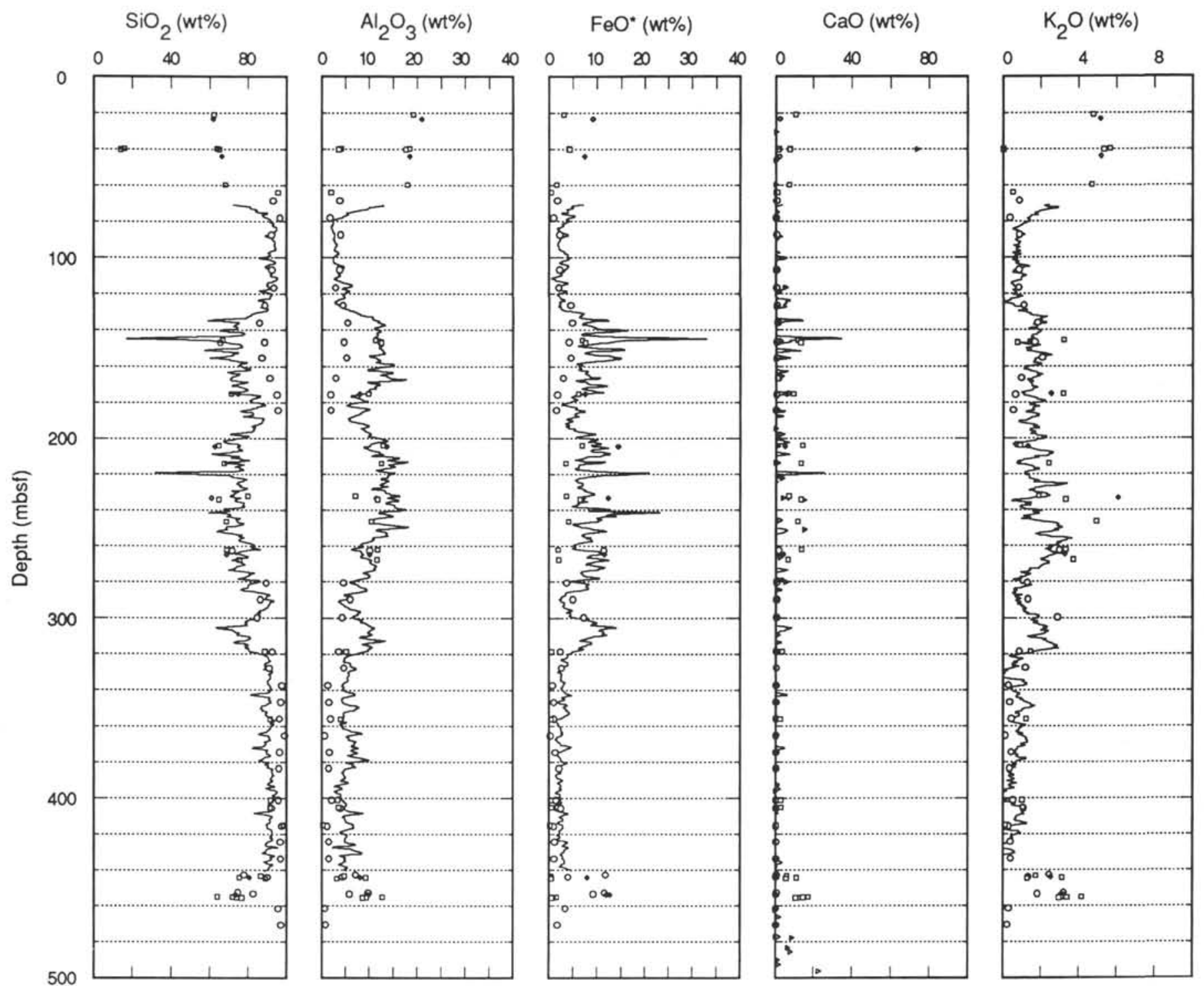

Figure 11. Normalized oxide contents of Site 801 sediments, from logs and laboratory determinations. Symbols are as in Figure 10, but with data from Shipboard Scientific Party (1990b).

the lowest velocity and density, plus relatively high silica, iron, aluminum and potassium contents. The most variable lithotype used for these inversions is "sandstone/tuff." The sandstone and tuff samples collected at all three sites display a wide range in properties, although the two lithologies have similar average values. Variations are as large within any one site as between sites. The lithotype is characterized by moderate-to-high concentrations of silica (largely as quartz grains in the sandstone and quartz plus glass shards in the tuff), aluminum, iron, and potassium and moderate densities and velocities. The differences between the two lithologies (sandstone at Sites 800 and 801; tuff at Site 802) are sufficiently significant that the assumed compositions and properties were varied accordingly to improve the results of the inversions.

Tables 1 and 2 summarize the properties of the lithotypes allowed in all the models. The values used for the inversions originated from a variety of sources. Bulk density, sonic slowness, and (normalized) calcium oxide data were available from shipboard measurements, and appeared to match the logged data well in zones within which recovery was high. Other geochemical data were provided prior to publi- cation by Karl and Karpoff (this volume), Behl (this volume), Karpoff (this volume), Karpoff et al. (this volume), and France-Lanord et al. (this volume). These values were normalized to be compatible with the five normalized oxides determined from the geochemical logs and used in this study. In addition, log data from isolated zones within which cores and logs suggested the presence of a single, dominant lithotype, were averaged to determine the expected log response. The final matrix values are a rough mix (really a compromise) of these different data sources.

\section{Stability of the Lithotype Model}

The selection of appropriate components requires that the lithotypes are (1) geologically reasonable and (2) statistically independent. As a test of independence, and of the ability of the seven chosen logs to discriminate among the lithotypes, we conducted a simple forward-modeling test. A lithologic column was created, with over 100 combinations of lithotypes; each component varied in abundance from 0 to $100 \%$ (by weight) of the total. Seven logs were 

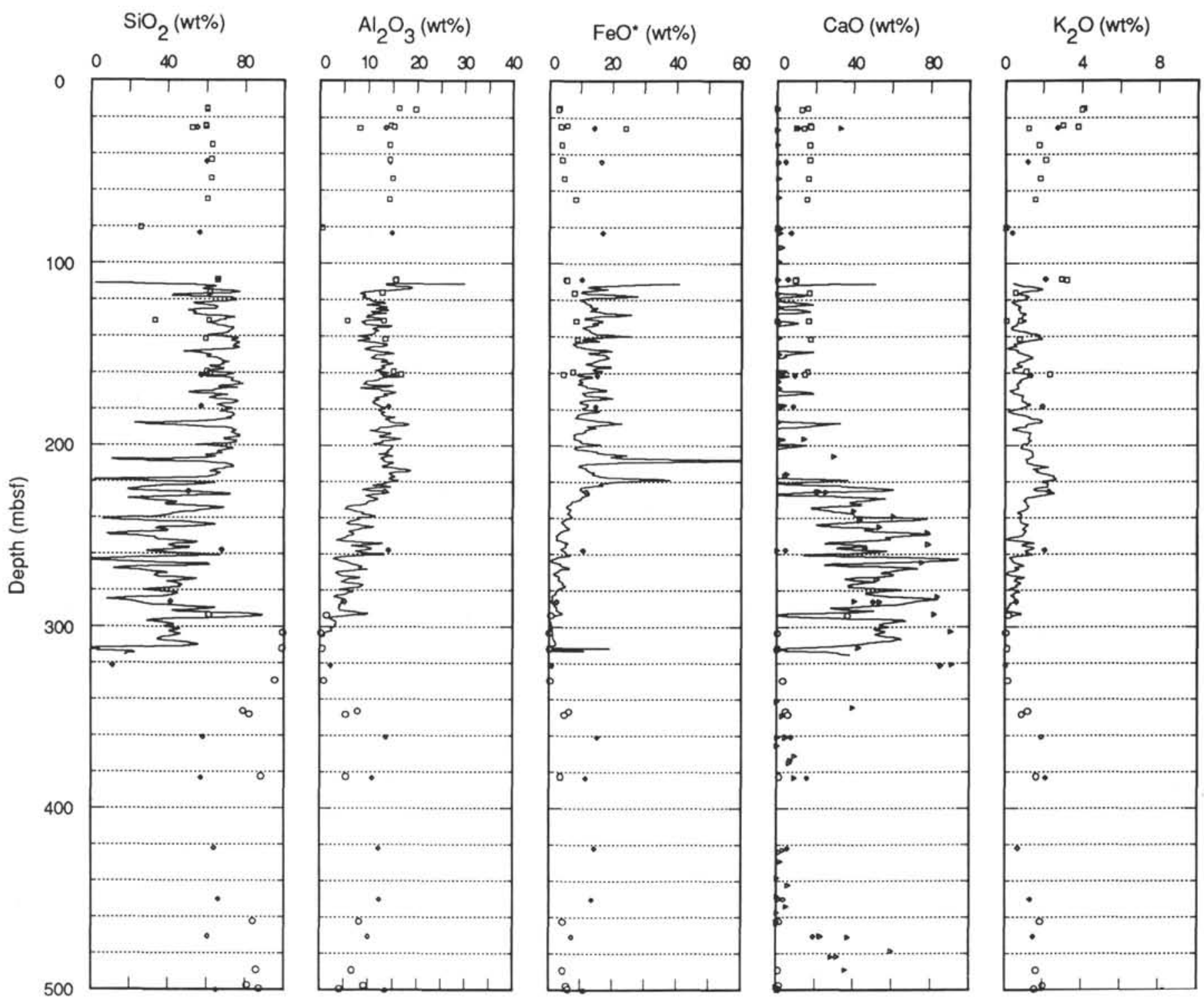

Figure 12. Normalized oxide contents of Site 802 sediments, from logs and laboratory determinations. Symbols are as in Figure 10, but with data from Shipboard Scientific Party $(1990 \mathrm{c})$. Note the unrealistically low silica and high iron values, which may reflect errors during acquisition or processing of the geochemical logging data.

then generated from this column (Fig. 14) and inverted. The resulting lithology column was then compared to the original column, yielding a standard error of $<1 \%$ in all cases (Fig. 15). This result shows that the lithotypes are independent and can be readily identified with the available logs. The test does not assure that the lithotypes are geologically reasonable, however, as this requires additional geological and geophysical evidence.

\section{Error Analysis}

With seven log types and a maximum of five lithotypes, the system of equations inverted for this study is over-determined, allowing for detailed error analysis (e.g., Doveton, 1986). The most basic error analysis involves a comparison of recorded and calculated tool responses, with the latter based on the estimated lithologic percentages. After calculation of the proportions of the various lithotypes, the tool responses to the modeled system were calculated, based on the original relationships assumed between each lithotype and tool (Tables 1 and 2). In an exactly-determined system (the number of tools equals the number of lithologies minus one) this analysis would be useless. In an over-determined system, particularly one in which the different tool responses have been weighted, this analysis will provide a rough indication of the numerical consistency of the model. It is still up to the geologist to evaluate the true "likeliness" of the modeled output.

Perhaps the most significant indicator is the negative sum error (NSE), the total of all proportions for which negative values were calculated during the inversion (Harvey et al., 1990). During the inversion of data from any one depth, negative proportions may be calculated if these values allow the best fit to the data. Geologically, negative proportions are impossible. The presence of large negative values following the inversion suggests that the assumed lithotypes and/or properties are inappropriate for the given data interval. Negative proportions may be calculated for several reasons. First, poorquality data or incorrect depth-shifting between logs can result in a search for a "phantom" lithotype, with some combination of properties that is unrealistic. The same effect can result from having too few 


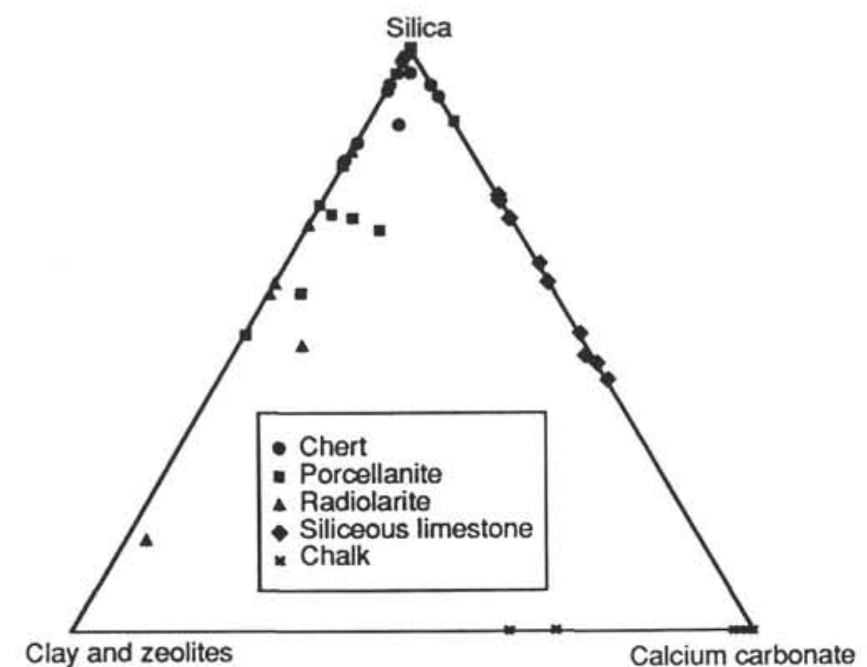

Figure 13. Ternary diagram of normalized X-ray diffraction data from Behl (this volume). All forms of silica (opal, tridymite, and cristobalite) were combined to calculate the "silica" component. These data illustrate that several lithologies identified during Leg 129 can be considered to be mixtures of end members with more extreme compositions. See text for discussion.

lithotypes. A model with too many poorly constrained lithotypes (intermediate types) can result in a matrix with singularities that never converges during inversion (effectively forming an error-space that is too "shallowly dished" for a minimum to be found).

Our program deals with negative proportions in several ways. First, one component is eliminated, and the inversion is repeated with one fewer acceptable lithotype. The elimination is continued, if necessary, until a minimum of two lithotypes remains. If there is still a high NSE (arbitrarily chosen to be decimal fraction 0.20 , or $20 \%$ ), then the solution with the smallest NSE is accepted. Negative proportions are then set equal to zero and the remaining proportions are normalized to add to $100 \%$.

Another useful error indicator is the standard error of the forwardmodeled logs, expressed as a percentage of the total original signal, which shows how well the final lithology column simulates the field data. We have designed our inversion program to correct the physical properties of clay-rich lithotypes as a function of depth, based on the property-depth rebound relationships defined previously (Figs. 2 and 3 ). This requires that the matrix of typical lithologic characteristics be inverted at every log-measurement depth of interest, but the computational price for this extra number crunching is small.

A more significant problem with log inversion which is not typically discussed (e.g., Doveton, 1986; Jarrard et al., 1989; Harvey et al., 1990) involves the numerical technique used to invert the log-lithology matrix. If the original matrix is simply inverted algebraically, with no regard to either machine precision or pivot size, enormous errors can be introduced (Carnahan et al., 1969). This problem is compounded when the typical values found in the original matrix vary in size by 2 or more orders of magnitude (e.g., with sonic slowness in units of microseconds per foot $[\mu \mathrm{s} / \mathrm{ft}]$ values of $80-200$ are common, while with potassium oxide content in weight percent, values near zero are common). The resulting difference in magnitude will cause a singleprecision computing device to introduce large rounding errors. We ran all analyses using double-precision storage and used IMSL subroutines that optimized matrix parameters to reduce numerical imprecision and provide warning flags for small pivot operations.

The greatest uncertainly in this study probably originates from the primary underlying assumption: all significant lithotypes present within the intervals logged during Leg 129 are directly or indirectly represented by the five possible lithotypes defined earlier. This as-
Table 1. Assumed properties and compositions of lithotypes used at Sites 800 and 801.

\begin{tabular}{lccrrrrr}
\hline Lithotype & $\begin{array}{c}\mathrm{\rho}_{\mathrm{b}} \\
\left(\mathrm{g} / \mathrm{cm}^{3}\right)\end{array}$ & $\begin{array}{c}1 / \mathrm{v} \\
(\mu \mathrm{s} / \mathrm{ft})\end{array}$ & $\begin{array}{c}\mathrm{SiO}_{2} \\
(\mathrm{wt} \%)\end{array}$ & $\begin{array}{r}\mathrm{Al}_{2} \mathrm{O}_{3} \\
(\mathrm{wt} \%)\end{array}$ & $\begin{array}{r}\mathrm{FeO} * \\
(\mathrm{wt} \%)\end{array}$ & $\begin{array}{r}\mathrm{CaO} \\
(\mathrm{wt} \%)\end{array}$ & $\begin{array}{r}\mathrm{K}_{2} \mathrm{O} \\
(\mathrm{wt} \%)\end{array}$ \\
\hline Pelagic clay & 1.38 & 200 & 73.0 & 13.4 & 4.7 & 3.9 & 2.3 \\
Clay/siltstone & 1.84 & 158 & 71.2 & 5.9 & 9.0 & 7.4 & 1.3 \\
Chert & 2.52 & 62 & 95.4 & 2.0 & 1.5 & 4.0 & 0.5 \\
Chalk & 2.00 & 142 & 18.0 & 1.5 & 1.0 & 79.0 & 0.5 \\
Sandstone & 1.90 & 118 & 80.0 & 10.6 & 9.0 & 0.1 & 1.2 \\
aWeight & 1.0 & 1.0 & 0.8 & 0.6 & 0.6 & 1.0 & 0.6 \\
\hline
\end{tabular}

Note: The selection and characterization of lithotypes is discussed in the text. Oxide contents are based on normalized geochemical data from Shipboard Scientific Party (1990a, 1990b), Behl et al. (this volume), Karl et al. (this volume), and Karpoff et al. (this volume), and from selection of single-lithotype intervals from the logs. Calcium carbonate was normalized to $\mathrm{CaO}$.

"Weights are subjective, and are based on the assumed accuracy of the individual logs plus the importance placed, on each log in terms of its ability to discriminate lithotypes.

Table 2. Assumed properties and compositions of lithotypes used at Site 802.

\begin{tabular}{lccrrrrr}
\hline Lithotype & $\begin{array}{c}\rho_{\mathrm{b}} \\
\left(\mathrm{g} / \mathrm{cm}^{3}\right)\end{array}$ & $\begin{array}{c}\mathrm{1} / \mathrm{v} \\
(\mu \mathrm{s} / \mathrm{ft})\end{array}$ & $\begin{array}{c}\mathrm{SiO}_{2} \\
(\mathrm{wt} \%)\end{array}$ & $\begin{array}{r}\mathrm{Al}_{2} \mathrm{O}_{3} \\
(\mathrm{wt} \%)\end{array}$ & $\begin{array}{r}\mathrm{FeO}^{*} \\
(\mathrm{wt} \%)\end{array}$ & $\begin{array}{c}\mathrm{CaO} \\
(\mathrm{wt} \%)\end{array}$ & $\begin{array}{c}\mathrm{K}_{2} \mathrm{O} \\
(\mathrm{wt} \%)\end{array}$ \\
\hline Pelagic clay & 1.38 & 200 & 68.9 & 16.4 & 6.7 & 3.9 & 2.3 \\
Clay/siltstone & 1.84 & 158 & 66.2 & 8.9 & 11.0 & 7.4 & 1.3 \\
Chert & 2.52 & 62 & 95.4 & 2.0 & 1.5 & 4.0 & 0.5 \\
Chalk & 2.00 & 142 & 8.0 & 1.5 & 1.0 & 89.0 & 0.5 \\
Tuff & 1.85 & 111 & 65.0 & 13.6 & 15.0 & 7.1 & 1.3 \\
${ }^{\text {aWf }}$ Weight & 1.0 & 1.0 & 0.8 & 0.6 & 0.6 & 1.0 & 0.6 \\
\hline
\end{tabular}

Note: The selection and characterization of lithotypes is discussed in the text. Oxide contents are based on normalized geochemical data from Shipboard Scientific Party (1990c), Behl et al. (this volume), Karl et al. (this volume), and Karpoff et al. (this volume), and from selection of single-lithotype intervals from the logs. Calcium carbonate was normalized to $\mathrm{CaO}$.

"Weights are subjective, and are based on the assumed accuracy of the individual logs plus the importance placed on each log in terms of its ability to discriminate lithotypes.

sumption requires that all significant lithologies within the section at any one site are represented in the cores recovered during the cruise.

\section{Lithotype Inversions from Sites $\mathbf{8 0 0 , 8 0 1}$, and 802}

Figure 16 graphically illustrates the modeled lithotypes determined with the inversion procedure described previously for the logged interval (50 to $275 \mathrm{mbsf}$ ) in Hole $800 \mathrm{~A}$, with all quantities reported in weight percent. Pelagic clay content is generally greater than $20 \%$, and is highest overall within lithologic Units II and IV. The proportion of chert is $30 \%$ to $40 \%$ through most of Units II and III, although the abundance of this lithotype drops to near zero between 130 and 140 mbsf within Unit III. This depth corresponds to a predicted peak in the chalk lithotype, which was relatively rare in the cores recovered from this section of Hole $800 \mathrm{~A}$. The predicted high chalk content at $80-140$ mbsf reflects relatively high calcium content and low velocities. The actual lithology sandwiched between thin chert beds at Site 800 could also be a clay-rich, calcium carbonate ooze; it is certainly soft and calcium rich. The 160-190 mbsf interval includes both high predicted chalk $(>30 \%)$ and high predicted chert $(>25 \%)$ lithotypes and may actually be composed largely of siliceous limestone, rather than a chalk/chert mixture. Recovery was poor throughout this interval, but included a significant proportion of siliceous limestone (Shipboard Scientific Party, 1990a).

The sandstone lithotype makes a first significant appearance near $220 \mathrm{mbsf}$, somewhat higher than the top of lithologic Unit IV (Fig. 16). 

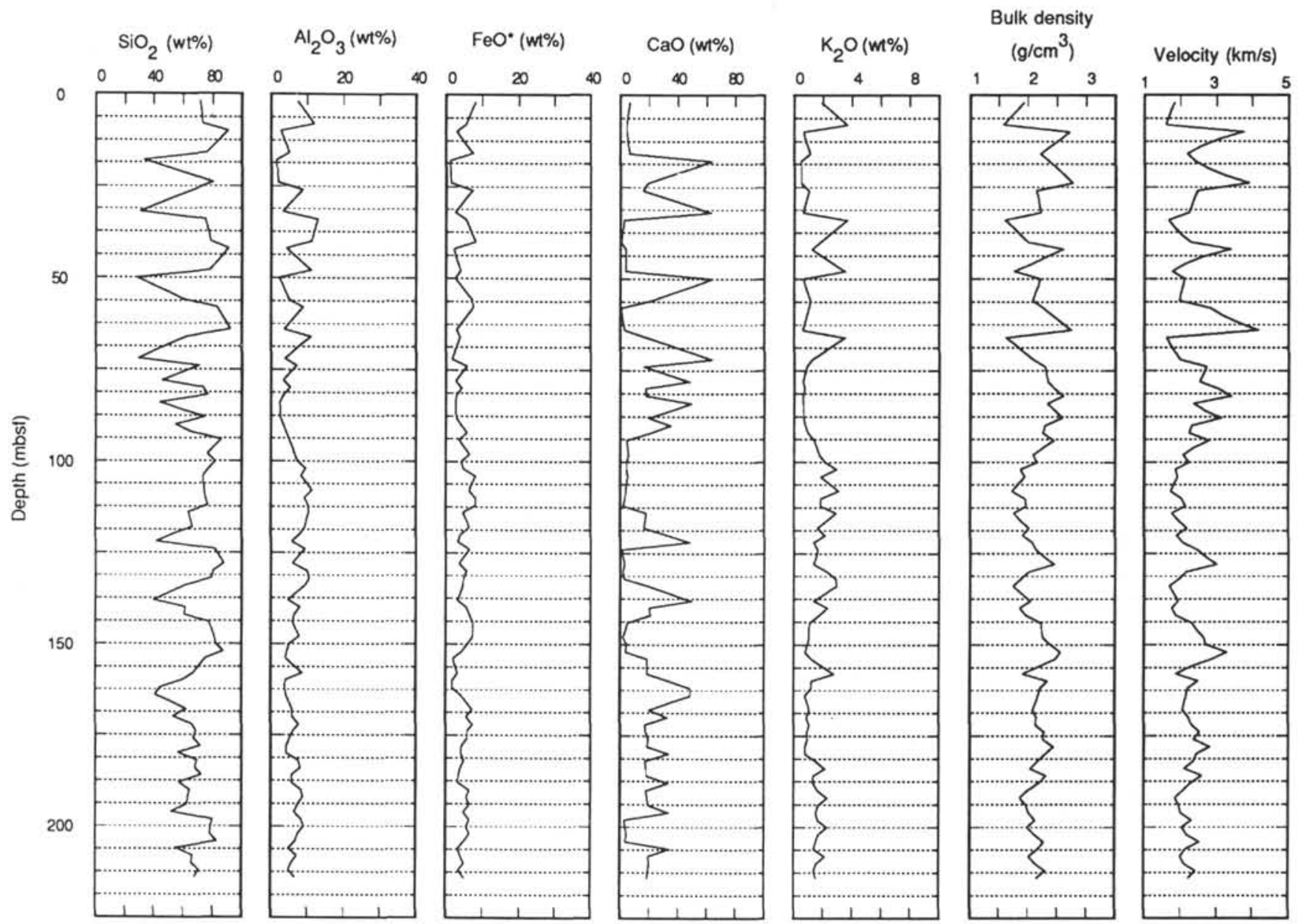

Figure 14. Synthetic oxide and physical-properties logs calculated from an idealized lithologic section composed of mixtures of the five primary lithotypes chosen for use in this study. All possible combinations of mixtures, with weight increments of $20 \%$, were used in this test of inversion stability. Depths are arbitrary.

The dominant lithotypes predicted below this depth (sandstone, clay/siltstone, pelagic clay) are the main components that form volcaniclastic turbidites, which characterize this unit. One interesting exception is the zone between 260 and 270 mbsf, which is predicted to contain a significant chert component, coinciding with the first significant return of porcellanite in the recovered core. It seems geologically unlikely that actual pelagic clay, as cored in lithologic Unit I, is present within the Cretaceous volcaniclastic turbidites of lithologic Unit IV, but the predicted presence of this lithotype reflects the relatively low velocities, low calcium content, and high aluminum content of this part of the logged interval. Removing pelagic clay from the list of possible lithotypes greatly increases the NSE of the inversion because negative proportions of other lithotypes are required to account for the observed low velocity and low calcium content of several intervals. The standard error of the inversion at Site 800 is very low, and the NSE averages about 0.1 , although some zones have values above 0.2 .

The inversion at Site 801 yielded a quantitatively poorer estimate of the primary lithotypes present throughout the logged interval (80-440 mbsf; Fig. 17). The standard error of the fit is higher overall than at Site 800 (although still generally less than 5\%), whereas the negative sum of the errors reveals several thin zones with a poor fit. Chert appears to compose about $40 \%$ of the lower part of lithologic Unit II, and then appears in two parts of Unit III, 180-200 and 280-300 mbsf, both intervals of extremely poor recovery (Shipboard Scientific Party, 1990b). The sandstone lithotype is predicted mainly within the boundaries of lithologic Unit III, composing as much as
$80 \%$ of the total rock mass, whereas chalk is absent throughout most of the logged interval. A large increase in the predicted chert content corresponds to the top of lithologic Unit IV, and is clearly consistent with the appearance of radiolarite, porcellanite, and chert in the cores. Material not recovered throughout this interval of Hole 801B could well be more radiolarite (rather than some softer material such as pelagic clay) as the idealized lithotypes of chert and pelagic clay could be combined.

The inversion of logs for lithologies was least effective at Site 802 (Fig. 18), which is surprising at first, considering the good match of the laboratory and log physical-properties data. The standard error of the fit is significantly higher than at Sites 800 and 801 , and the negative sum of the errors averages about 0.20 . More troubling, there are many sections of the hole within which the NSE exceeds 0.5 , and a few where it is greater than 1.0. Very high NSE values suggest either that the logs are bad over the interval in question, or that the assumed lithotypes and characteristics used in the inversion are inappropriate. The latter could easily result because (1) there is at least one major lithotype that has been left out (the set is incomplete), (2) one or more of the assumed lithotypes has been assigned incorrect average parameters, and/or (3) there is such extreme variation in properties such that inversion for lithology is impossible at this depth. We attempted to improve the model of Hole $802 \mathrm{~A}$ with different combinations of four and three possible lithotypes and by altering the expected compositions of the lithotypes, but the quality of the fit did not improve appreciably. It is revealing that several parts of the logged interval at Site 802 include unrealistically low silica and high iron contents 


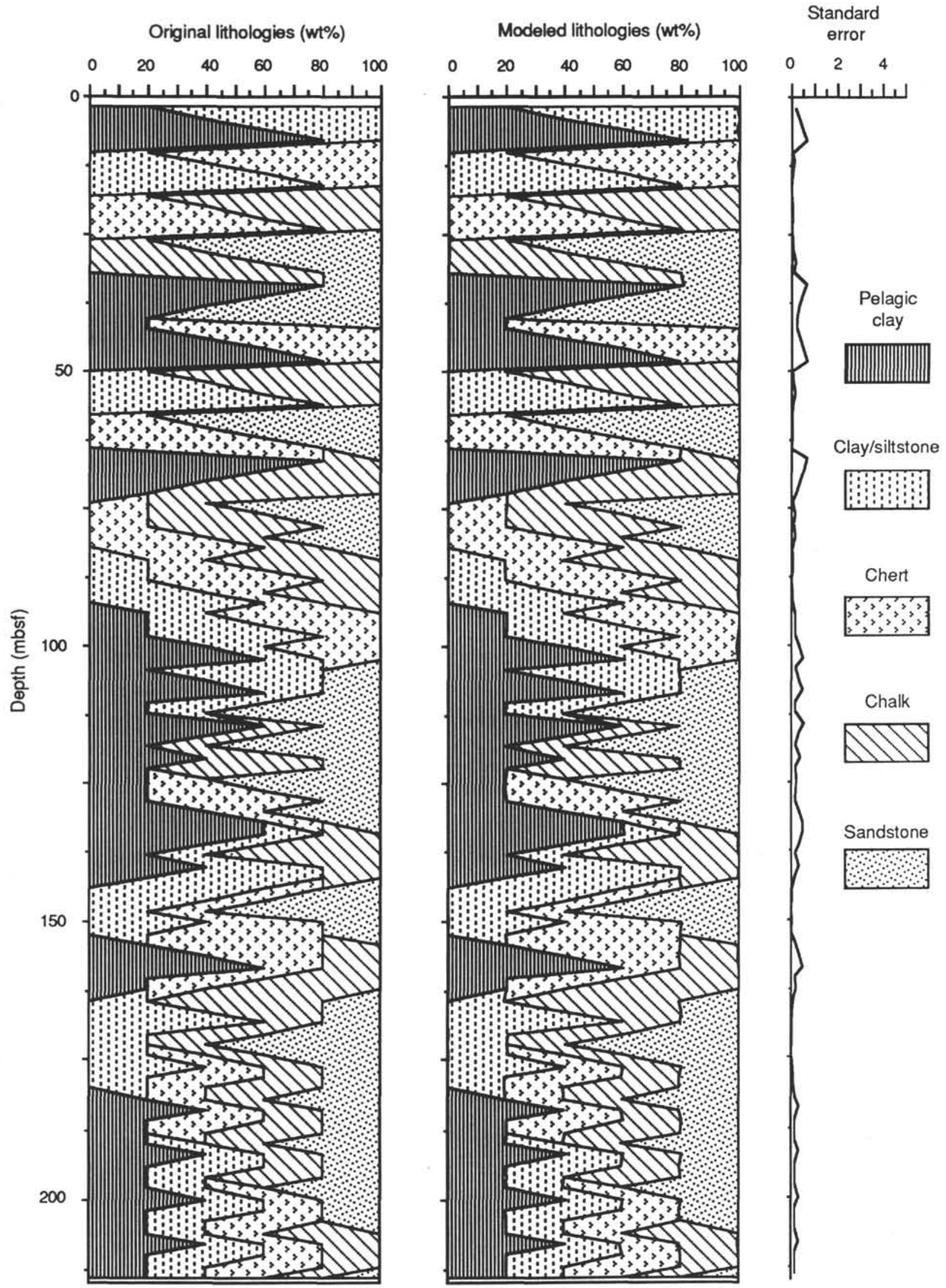

Figure 15. Original (synthetic) and modeled lithologic sections illustrate that (1) the five primary lithotypes used in this study are statistically independent and (2) the five oxide and two physical properties logs are adequate to distinguish between the lithotypes. The standard error is based on the difference between synthetic logs which would be expected from the two lithology columns shown. 


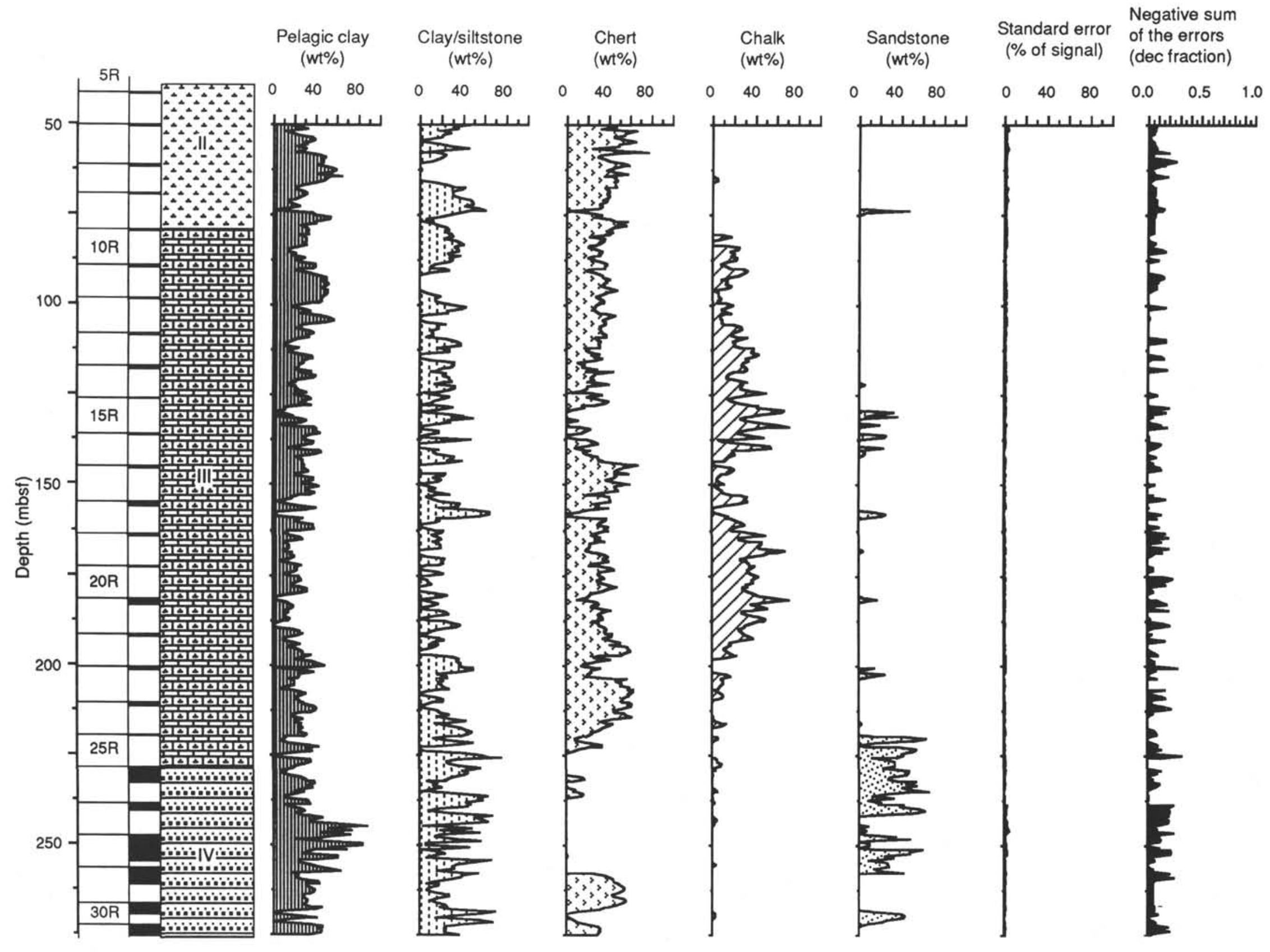

Figure 16. Results of an inversion of the five oxide and two physical-properties logs from Site 800. The column on the left illustrates cored intervals and recovery, along with the lithology column from Shipboard Scientific Party (1990a). Each of the next five columns illustrate the weight percent of each idealized lithotype that best fits the log data. The two columns on the right give some indication of the goodness-of-fit of the model to the data, as described in the text. 
(Fig. 12), perhaps due to a problem in calibration of the logging tool or in basic processing. One could accommodate this kind of problem by reducing the weight applied to the silica and iron signals, but this would result in an effectively underdetermined system, as these data are needed to discriminate between several lithotypes.

Despite the poor fit over parts of the logged interval, the modeled output may predict reasonable trends within several zones. A large increase in predicted chalk content (from essentially zero to $30-40 \%$ ) takes place near the boundary between lithologic Units II and III, while the predicted proportion of sandstone drops dramatically. The sandstone/pelagic clay ratio within Unit II appears to drop off with depth, as was observed in the cores (Shipboard Scientific Party, 1990c). The model also predicts several significant, isolated accumulations of chert within Unit III (Fig. 18). The corrected laboratory porosities from Hole $802 \mathrm{~A}$ match well with the synthetic log porosities (which are based on the borehole lithodensity log and a mean grain density determined for each depth from the inversion described above) indicating that the physical properties data set is self consistent, as are the general trends in the inverted lithology columns (Fig. 7A).

\section{DISCUSSION AND SUMMARY}

A wide variety of lithologies was cored and recovered during Leg 129, although statistical representation of the drilled section is probably poor. Several of the cored lithologies are easily distinguished on the basis of consistent physical and chemical parameters, whereas others are better classified as mixtures of more extreme end members. Of the lithologies represented in cores, only those rich in clay appear to require significant rebound corrections. A closed set of lithotypes was defined, based on the variety of sediment types observed during Leg 129, and a combined set of logs was inverted to determine the relative proportions of each lithotype present throughout the logged interval.

The subjective "quality" of these inversions, as indicated by the NSE values, appears to correlate well with the size of the "normalization factors" used by Pratson et al. (this volume, their Figs. 4, 6, and 8) to invert the original geochemical logging data to generate oxide estimates. These authors suggest that the size of the normalization factor (NF) reflects the quality of the "counting statistics" (with a lower NF reflecting better data), but a large NF could also indicate errors in instrument calibration, depth shifting, or data processing. More significantly, the good correlation between the large NF and large NSE values suggests that at least part of the inaccuracy associated with the analysis presented here was introduced prior to the classification of lithotypes and subsequent inversion.

The inversion of data from Hole 802A may reveal the greatest limitation of this method, that it requires some a priori knowledge of the composition (or at least the closed set of possible compositions) of the various lithologies within each interval of the logged hole. The forms of error analysis available for checking lithologic inversions are most rigorous in terms of numerical consistency, but do not directly address problems related to missing or incorrectly characterized lithotypes. A variety of optimization schemes could be employed to improve the fit by modifying the chemistry or properties of the acceptable lithotypes (within a range constrained by laboratory data) but there is no way to test directly the validity of the resulting inversion. We attempted an optimization scheme in which the number of acceptable lithologies was varied to find the best statistical fit to the log data, but found that the solutions were often unstable, with no quantitatively reliable means for choosing one model over another. Instead, it probably makes the most sense to look at general trends in the modeled output and interpret the logged interval accordingly.

The inversion of data from Site 800 suggests that pelagic clay comprises the missing lithology within Unit II, whereas chalk and pelagic clay lithotypes (as defined in this paper), or perhaps chalky radiolarite, porcellanite, or some combination of the preceding, comprises the missing material within Unit III. It is unlikely that more than about $30 \%$ of this missing material is actually chert or siliceous limestone, as the densities and velocities of these lithologies (Fig. 8) are too high in comparison to the log and interval means (Fig. 9).

In contrast, there is probably little chalk and significantly more clay and claystone within the logged units at Site 801 . The turbidites of Unit III appear to be coarser overall than those of the upper part of Unit IV at Site 801, based on the modeled sandstone and clay/siltstone lithotypes. Two significant "cherty" intervals have been identified within lithologic Unit III at Site 801 (possibly radiolarite, porcellanite, or true chert) and one such interval within the upper portion of Unit IV at Site 800. The composition of lithologic Unit IV at Site 801 appears to be relatively uniform, with approximately equal components of chert and pelagic clay lithotypes, and about half again as much clay/siltstone. In this interval, it appears that the recovered material is a better statistical sample than that of the overlying units.

This inversion procedure is useful where recovery is extremely low, but probably has greater utility when all the possible lithologies within a section are better characterized. This characterization might take place during drilling of a nearby borehole, or could result from core taken while drilling the hole in question if recovery is sufficiently high (perhaps $40 \%-60 \%$ ). In the latter case the lithotypes could be well defined, but there may still be a need to establish accurate estimates of the overall proportions of each lithologic component.

\section{ACKNOWLEDGMENTS}

Thanks to R. Behl, C. France-Lanord, S. Karl, A. Karpoff, and J. Ogg for providing sediment composition data prior to publication. Special thanks to the staff of the Borehole Research Group, and to Beth Pratson in particular, for their patience and assistance. Reviews by R. Wilkens and W. Brückmann were also appreciated. Acknowledgment is made to the donors of the Petroleum Research Fund, administered by the ACS, for partial support of this research. This work was also supported by the Ocean Drilling Program, and by USSAC grants 20408 (ATF), 20431 (LA), and 20425 (WHB).

\section{REFERENCES}

Archie, G. E., 1942. Electrical resistivity as an aid in determining some reservoir characteristics. Pet. Trans., AIME, 146:54-62.

Borehole Research Group, 1990. Ocean Drilling Program Logging Manual, LDGO.

Boyce, R. E., 1976. Definitions and laboratory techniques of the compressional sound velocity parameters and wet-water content, wet bulk density, and porosity parameters by gravimetric and gamma ray attenuation techniques. In Schlanger, S. O., Jackson, E. D., et al., Init. Repts. DSDP, 33: Washington (U.S. Govt. Printing Office), 931-958.

Busch, W. H., 1989. Patterns of sediment compaction at Ocean Drilling Program Sites 645, 646, and 647, Baffin Bay and Labrador Sea. In Srivastava, S. P., Arthur, M. A.,Clement, B., et al., Proc. ODP, Sci. Results, 105: College Station, TX (Ocean Drilling Program), 781-790.

Cannon, D. E., and Coates, G. R., 1990. Applying mineral knowledge to standard log interpretation. 31st Ann. Logging Symp., Soc. Prof. Well Log Analysts, Pap. V.

Carnahan, B., Luther, H. A., and Wilkes, J. O., 1969. Applied Numerical Methods: New York (Wiley).

Clavier, C., Coates, G., and Dumanoir, J., 1977. The theoretical and experimental basis for the "dual-water" model for the interpretation of shaly sands. Soc. Petrol. Eng., Pap. 6859.

Doveton, J. H., 1986. Log Analysis for Subsurface Geology: New York (Wiley)

Fulthorpe, C. S., Schlanger, S. O., and Jarrard, R. D., 1989. In situ properties of pelagic carbonate sediments on the Ontong Java Plateau. J. Geophys. Res., 94:4025-4032.

Hamilton, E. L., 1971. Prediction of in situ acoustic and elastic properties in marine sediments. Geophysics, 36:266-284.

1976. Variations of density and porosity with depth in deep-sea sediments. J. Sediment. Petrol., 46:280-300. 
Harvey, P. K., Bristow, J. F., and Lovell, M. A., 1990. Mineral transforms and downhole geophysical measurements. Sci. Drilling, 1:163-176.

Hertzog, R., Colson, L., Seeman, B., O’Brien, M., Scott, H., McKeon, D., Wraight, P., Grau, J., Schweitzer, J., and Herron, M., 1989. Geochemical logging with spectrometry tools. J. Soc. Petrol. Eng., 4:153-162.

Jarrard, R. D., Dadey, K. A., and Busch, W. H., 1989. Velocity and density of sediments of Eirik Ridge, Labrador Sea: control by porosity and mineralogy. In Srivastava, S. P., Arthur, M. A., Clement, B., et al., Proc. ODP, Sci. Results, 105: College Station, TX (Ocean Drilling Program), 811-835.

Lancelot, Y., Larson, R., et al., 1990. Proc. ODP, Init. Repts., 129: College Station, TX (Ocean Drilling Program).

Neumann, G., and Pierson, W. J., Jr., 1966. Principles of Physical Oceanography: Englewood Cliffs, NJ (Prentice-Hall).

Serra, O., 1986. Fundamentals of Well Log Interpretation: 2. The Interpretation of Logging Data: Amsterdam (Elsevier).

Shipboard Scientific Party, 1990a. Site 800. In Lancelot, Y., Larson, R., et al., Proc. ODP, Init. Repts., 129: College Station, TX (Ocean Drilling Program), 33-89.

1990b. Site 801. In Lancelot, Y., Larson, R., et al., Proc. ODP, Init. Repts., 129: College Station, TX (Ocean Drilling Program), 91-170. 1990c. Site 802. In Lancelot, Y., Larson, R., et al., Proc. ODP, Init. Repts., 129: College Station, TX (Ocean Drilling Program), 171-243.

van den Oord, R. J., 1990. Experiences with geochemical logging. 31st Ann. Logging Symp., Soc. Prof. Well Log Analysts, Pap. TT.

Von Herzen, R. P., Francis, T.J.G., and Becker, K., 1983. In situ large-scale electrical resistivity of oceanic crust, Hole 504B. In Cann, J. R., Langseth, M. G., Honnorez, J., Von Herzen, R. P., White, S. M., et al., Init. Repts. DSDP, 69: Washington (U.S. Govt. Printing Office), 237-244.

Waxman, M. H., and Smits, L.J.M., 1968. Electrical conductivities in oil-bearing shaly sands. J. Soc. Pet. Eng., 8:107-122.

Wendlandt, R. F., and Bhuyan, K., 1990. Estimation of mineralogy and lithology from geochemical log measurements. AAPG Bull., 74:837-856.

Winsauer, W. O., Shearin, H. M., Jr., Masson, P. H., and Williams, M., 1952. Resistivity of brine saturated sands in relation to pore geometry. AAPG Bull., 36:253-277.

Date of initial receipt: 29 May 1991

Date of acceptance: 2 December 1991

Ms 129B-138 


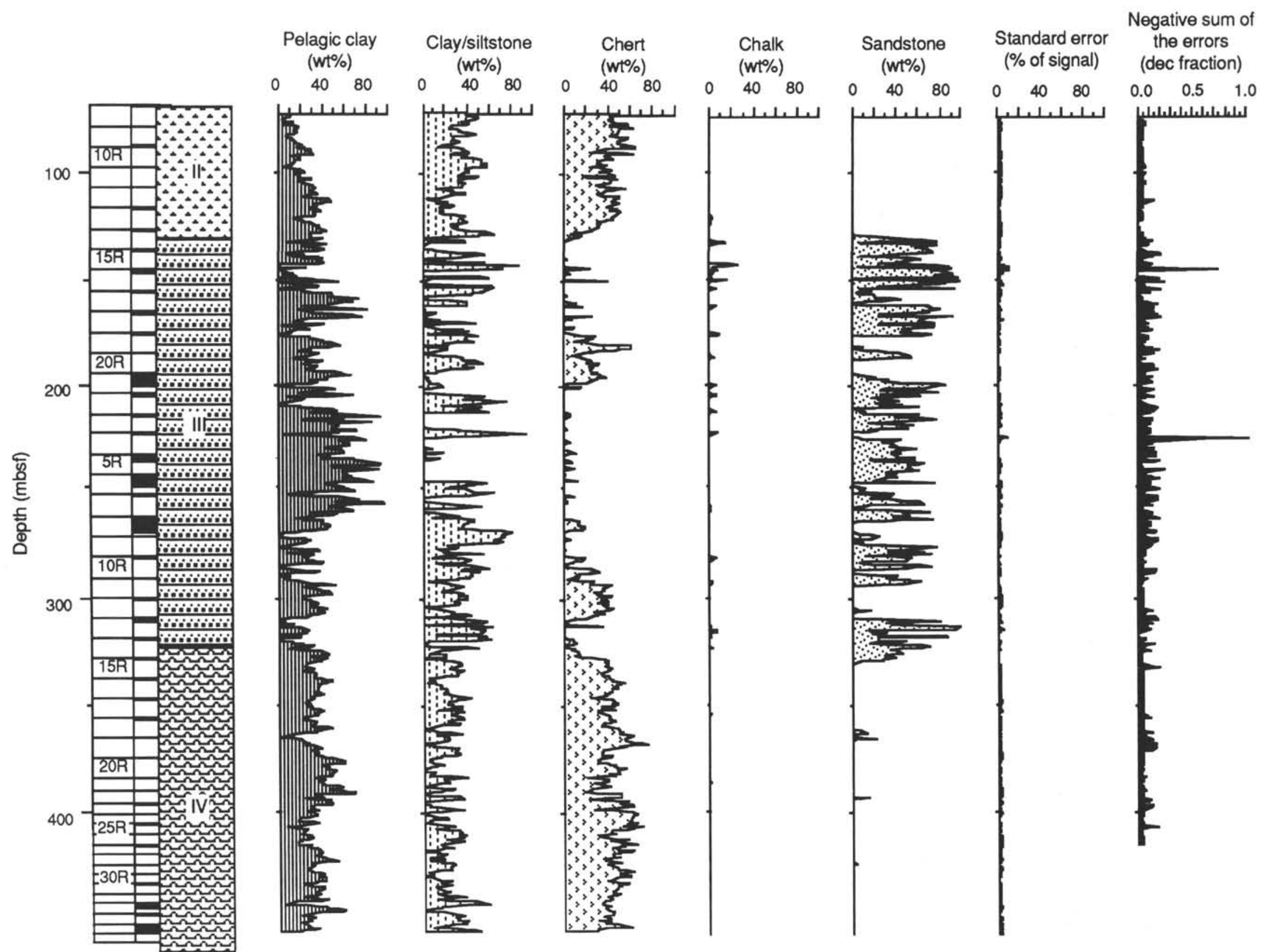




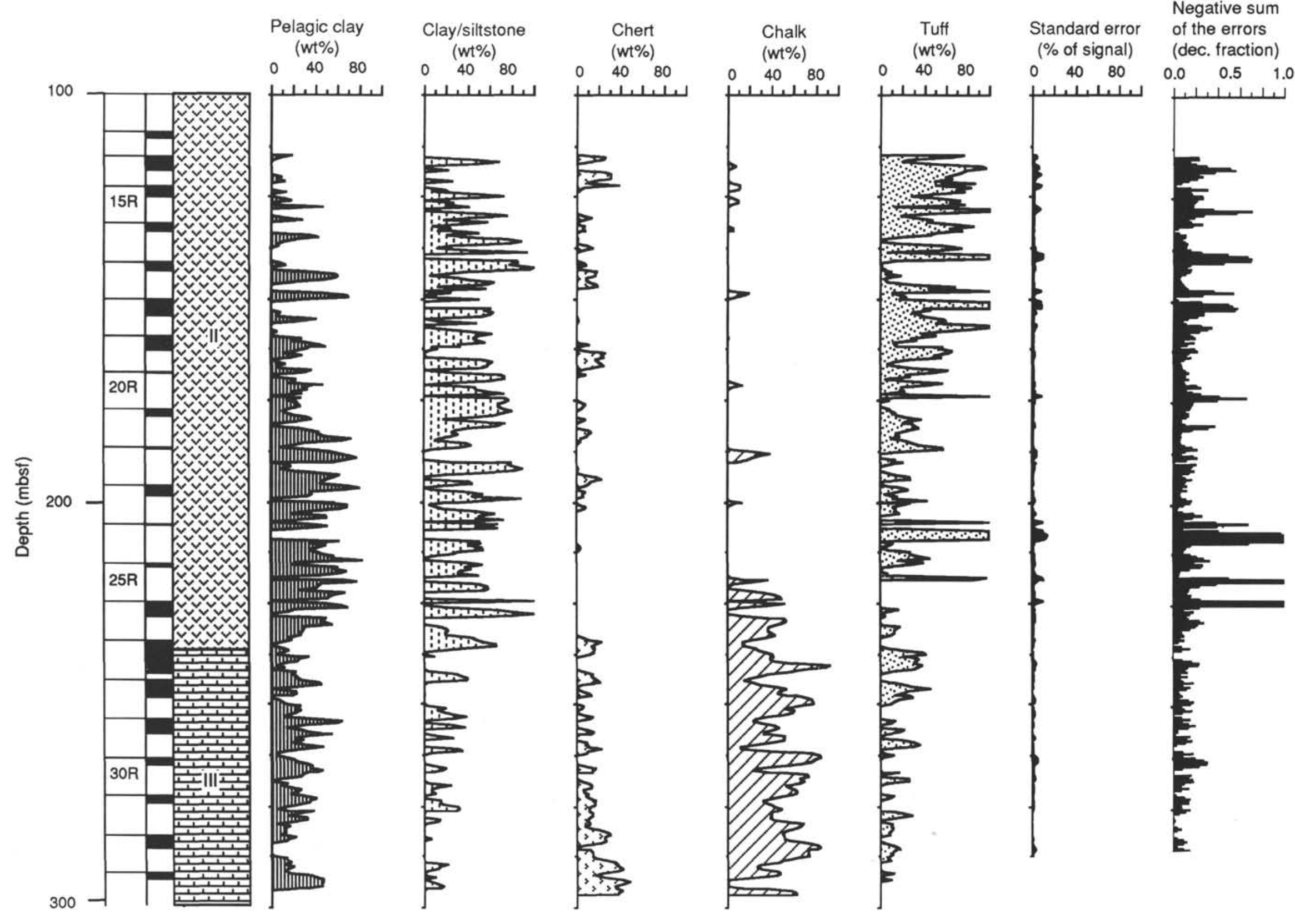

